\title{
Inhibition of SHP2 ameliorates the pathogenesis of systemic lupus erythematosus
}

\author{
Jianxun Wang, ${ }^{1}$ Masayuki Mizui, ${ }^{2}$ Li-Fan Zeng, ${ }^{3}$ Roderick Bronson, ${ }^{4}$ Michele Finnell, ${ }^{2}$ Cox Terhorst, ${ }^{5}$ Vasileios C. Kyttaris, ${ }^{2}$ \\ George C. Tsokos, ${ }^{2}$ Zhong-Yin Zhang, ${ }^{3}$ and Maria I. Kontaridis ${ }^{1,6}$ \\ 'Department of Medicine, Division of Cardiology, and 'Department of Medicine, Division of Rheumatology, Beth Israel Deaconess Medical Center (BIDMC), Boston, Massachusetts, USA. \\ ${ }^{3}$ Department of Biochemistry and Molecular Biology, Indiana University School of Medicine, Indianapolis, Indiana, USA. ${ }^{4}$ Department of Pathology, Harvard Medical School, Boston, Massachusetts, USA. \\ ${ }^{5}$ Department of Medicine, Division of Immunology, BIDMC, Boston, Massachusetts, USA. ${ }^{6}$ Department of Biological Chemistry and Molecular Pharmacology, Harvard Medical School, \\ Boston, Massachusetts, USA.
}

Systemic lupus erythematosus (SLE) is a devastating multisystemic autoimmune disorder. However, the molecular mechanisms underlying its pathogenesis remain elusive. Some patients with Noonan syndrome, a congenital disorder predominantly caused by gain-of-function mutations in the protein tyrosine phosphatase SH2 domain-containing PTP (SHP2), have been shown to develop SLE, suggesting a functional correlation between phosphatase activity and systemic autoimmunity. To test this directly, we measured SHP2 activity in spleen lysates isolated from lupus-prone MRL/Ipr mice and found it was markedly increased compared with that in control mice. Similar increases in SHP2 activity were seen in peripheral blood mononuclear cells isolated from lupus patients relative to healthy patients. To determine whether SHP2 alters autoimmunity and related immunopathology, we treated MRL/Ipr mice with an SHP2 inhibitor and found increased life span, suppressed crescentic glomerulonephritis, reduced spleen size, and diminished skin lesions. SHP2 inhibition also reduced numbers of double-negative T cells, normalized ERK/MAPK signaling, and decreased production of IFN- $\gamma$ and IL-17A/F, 2 cytokines involved in SLE-associated organ damage. Moreover, in cultured human lupus T cells, SHP2 inhibition reduced proliferation and decreased production of IFN- $\gamma$ and IL-17A/F, further implicating SHP2 in lupus-associated immunopathology. Taken together, these data identify SHP2 as a critical regulator of SLE pathogenesis and suggest targeting of its activity as a potent treatment for lupus patients.

\section{Introduction}

Systemic lupus erythematosus (SLE) is a devastating, multifactorial autoimmune disease caused by a panoply of immunoregulatory, genetic, environmental, hormonal, and epigenetic components. The pathogenesis of SLE includes both the innate and adaptive branches of the immune response $(1,2)$, involving both $B$ and $\mathrm{T}$ lymphocytes and affecting the function of monocytes, macrophages, dendritic cells, and other cellular and humoral components (3). T cells, which infiltrate vital organs and tissues, e.g., blood, spleen, kidney, lung, and brain, often produce proinflammatory cytokines that ultimately cause organ damage $(1,4)$. Double negative T cells (DN T cells, $\mathrm{CD} 3^{+} \mathrm{CD} 8^{-} \mathrm{CD} 4^{-\mathrm{TCR}} \alpha \beta^{+}$) infiltrate the kidney of SLE patients and lupus-prone MRL/MpJ-fas $l p r$ (MRL/lpr) mice and are major contributors to the lymphadenopathy and splenomegaly phenotypes in lupus (5). In addition, autoreactive B cells in SLE function to produce autoantibodies, causing accumulation of immune complexes and induction of inflammatory responses in tissues (6).

Authorship note: M. Mizui and L.F. Zeng contributed equally to this work. Conflict of interest: M.I. Kontaridis, Z.Y. Zhang, J. Wang, and L.F. Zeng have a patent pending on use of SHP2 inhibitors in SLE (WO2015003094 A2). Funding for a portion of this work was provided by GSK.

Submitted: February 11, 2016; Accepted: April 20, 2016.

Reference information: / Clin Invest. 2016;126(6):2077-2092. doi:10.1172/JCI87037.
Aberrant expression of immunoregulatory signaling proteins contributes to tissue injury and clinical manifestation of SLE. For example, kinases, such as calcium/calmodulin-dependent protein kinase IV (CaMK4), are increased in SLE T cells and are involved in the transcriptional regulation of genes that lead to the impairment of cytokine production (7), Similarly, abnormalities in genes encoding protein phosphatases are also causally involved in autoimmunity. For example, protein phosphatase 2A (PP2A) is induced in both expression and activity in $\mathrm{T}$ cells, promoting inflammation through aberrant cytokine production and tissue infiltration (8). The C1858T allele of protein tyrosine phosphatase, non-receptor type 22 (PTPN22) confers increased risk for SLE, rheumatoid arthritis (RA), and type 1 diabetes, likely through dysregulation of its binding to the C-terminal Src tyrosine kinase (Csk), and thereby leads to aberrant regulation of $\mathrm{T}$ cell activation (9-12). In addition, a mutation in $C D 45,77 \mathrm{C} / \mathrm{G}$, is linked to the onset of autoimmune hepatitis (13). More recently, an SLE susceptibility locus on chromosome 12 (12q24) was identified in the same region as the SH2 domain-containing PTP (SHP2) (14), suggesting that it too may be involved in the pathology and/or progression of SLE, although this has not yet been determined.

SHP2 is a nonreceptor PTP containing 2 SH2 domains, a catalytic PTP domain and a C-terminal tail with 2 tyrosine phosphorylation sites and a proline-rich motif (15-17). While normally inactive in the basal state, binding of a phosphotyrosyl (pY) 
protein to SHP2 alters its conformation, unfolding the enzyme and activating the phosphatase to elicit downstream signaling (18-20). Missense SHP2 mutations are found in approximately $50 \%$ of cases of Noonan syndrome (NS), a common ( 1:10001:2500) autosomal dominant disorder characterized by multiple, variably penetrant defects $(21,22)$. Nearly all NS mutations of SHP2 are catalytically hyperactivated, i.e., they have increased PTP activity $(23,24)$ and behave as gain-of-function (GOF) alleles (23-29). Importantly, to date, over 50 cases of NS have been linked to the development of SLE, as demonstrated by the onset of polyarthritis, pericarditis, and production of antinuclear and anti-DNA antibodies in these patients (30-35). Taken together, these data suggest that a functional and/or genetic association between SLE and SHP2 activity likely exists.

Despite numerous efforts to understand the cellular and mechanistic complexities of SLE, no unifying hypothesis exists to explain the role of altered signal transduction networks in the pathogenesis of this disease. Here, for what we believe is the first time, we provide evidence that SHP2 activity is increased in both lupus-prone mice and in human SLE patients. Further, its inhibition increases life span, suppresses crescentic glomerulonephritis, reduces spleen size, and diminishes skin lesions in MRL/lpr mice. Treated mice also have reduced numbers of DN T cells, normalized ERK/MAPK signaling, and decreased production of IFN- $\gamma$ and IL-17A/F, critical cytokines involved in SLE-associated organ damage and also found to be increased in human SLE patient serum. Moreover, the SHP2 inhibitor reduces the proliferation of cultured human lupus $\mathrm{T}$ cells and decreases the production of IFN- $\gamma$ and IL-17A/F in vitro, further implicating SHP2 in human lupus-associated immunopathology. Taken together, we identify SHP2 as a critical regulator of SLE disease and suggest targeting of its activity as a potent therapy for lupus patients.

\section{Results}

SHP2 activity is increased in human SLE patients and in lupus-prone $M R L / l p r$ mice. To assess whether SHP2 has any functional consequence in SLE pathogenesis, we performed an immune-complex phosphatase assay to measure SHP2 activity in human peripheral blood mononuclear cells (PBMCs) isolated from normal female donors or SLE disease-active female patients. SHP2 activity was significantly increased ( 4 -fold) in lupus PBMCs, as compared with normal cells, suggesting SHP2 activity is altered in human SLE disease (Figure 1A). We next utilized lupus-prone MRL/lpr mice, a murine model that recapitulates human disease and in which SLE susceptibility correlates with mutations at several loci $(36,37)$. These mice also contain an autosomal recessive lpr (lymphoproliferation) gene mutation, which is thought to be causal to the early onset (12 weeks of age) of the disease, which includes severe lymphadenopathy, autoantibody production, circulating immune complexes, glomerulonephritis, splenomegaly, arthritic changes, pulmonary lesions, progressive histopathologic changes, including lymphocytic and monocytic cell infiltrations, and destruction of normal tissue architecture, and which culminates in death by approximately 24 weeks of age (38). For experimental controls, we used female C57BL/6 WT mice as well as the lupus background strain MRL/MpJ mice, which do not have the recessive lpr gene mutation, but develop a milder and later-onset arthri- tis and glomerulonephritis phenotype (38). We performed an immune-complex phosphatase assay in spleen lysates generated from 18-week-old WT, MRL/MpJ, and MLR/lpr female mice and found that SHP2 activity, as in human lupus PBMCs, was significantly increased ( 5 -fold higher) in MLR/lpr mice, as compared with both WT and MRL/MpJ controls (Figure 1B).

To determine whether SHP2 activity affects lupus pathogenicity, we utilized a hydroxyindole carboxylic acid-based SHP2 inhibitor (11a-1) that anchors to the SHP2 active site, with strong potency $\left(\mathrm{IC}_{50} 200 \mathrm{nM}\right)$ and selectivity (>5-fold against any of 20 other PTPs) (39). We treated WT, MRL/MpJ, and MRL/lpr female mice with either vehicle or 11a-1 $(7.5 \mathrm{mg} / \mathrm{kg} / \mathrm{d})$ for a period of 6 weeks, beginning at 12 weeks, the age of SLE disease onset in MRL/lpr mice. Immune complexes derived from spleens isolated from SHP2 inhibitor-treated MRL/lpr mice showed normalized SHP2 activity, with no effects of the inhibitor in WT or MRL/MpJ lysates (Figure 1B). Importantly, the inhibitor was specific to SHP2, as activity of PTPN22, another tyrosine phosphatase upregulated and involved in SLE pathogenesis, or SHP1, a closely related SHP family member, was not affected by treatment with the SHP2 inhibitor (Supplemental Figure 1, A and B; supplemental material available online with this article; doi:10.1172/JCI87037DS1). Moreover, 11a-1 treatment was potent and reversible, as SHP2 activity returned to the same level as that of vehicle-treated lysates following serial washes of the SHP2 immune-complex (Supplemental Figure 1C).

SHP2 modulates ERK/MAPK, but not AKT/mTOR, signaling in $S L E$. PI3K/AKT/mTOR signaling is an important pathway regulated by SHP2 (40) whose activation promotes survival as well as cytokine/inflammatory signaling in SLE (41). Here, and consistent with inflammatory responses that can activate this pathway, MRL/lpr spleen lysates showed increased phosphorylation of both AKT and p70s6K, the downstream effector of mTOR, in 18-week-old MRL/lpr female mice (Figure 1C). However, 11a-1 drug treatment did not normalize the aberrant AKT or p70S6K activities (Figure 1C), suggesting SHP2 plays a modest role, if any, in this signaling pathway in SLE disease.

SHP2 is also a key positive regulator of ERK/MAPK signaling by nearly all receptor tyrosine kinase, cytokine, and integrin receptors $(15-17,42)$. Aberrant regulation of this pathway therefore could contribute to immune dysfunction in lupus through epigenetic effects on gene expression $(43,44)$. Indeed, decreased ERK/MAPK signaling in T cells is associated with abnormal epigenetic modification and overactivation of $\mathrm{T}$ cells (45). To assess the effects of increased SHP2 activity on ERK signaling in SLE, we measured ERK1/2 phosphorylation in spleen lysates isolated from 18-week-old WT, MRL/MpJ, and MLR/lpr female mice. Despite elevated SHP2 phosphatase activity, which normally induces ERK phosphorylation, we found that ERK/MAPK activity was significantly decreased in MRL/lpr lysates, as compared with WT and $\mathrm{MRL} / \mathrm{MpJ}$ controls (Figure 1D); indeed, this result is consistent with previous observations of ERK/MAPK activity in SLE-prone mice (46). Importantly, 11a-1 reversed the aberrant ERK/MAPK signaling in MRL/lpr splenocytes (Figure 1D), suggesting signaling specificity of SHP2 for this pathway in SLE.

Normalization of SHP2 activity ameliorates skin lesions, increases life span, and reduces lupus-associated organ damage in lupus-prone $M R L /$ pr mice. To delineate the contribution of SHP2 activity on 

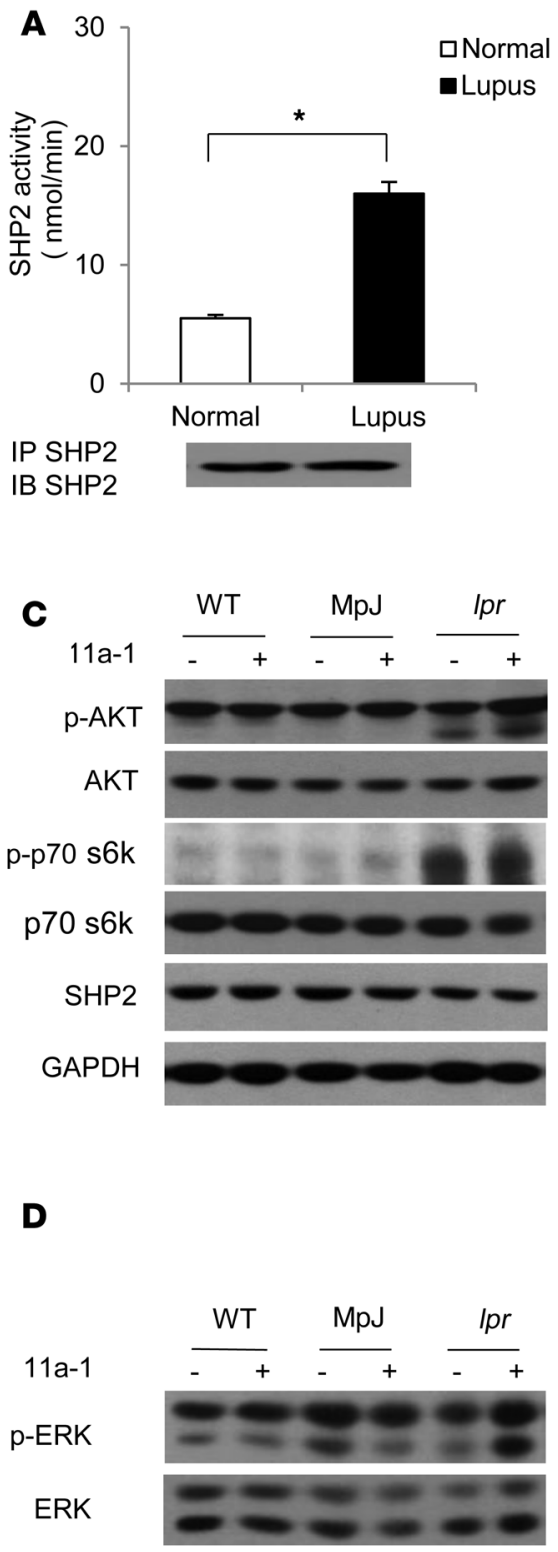
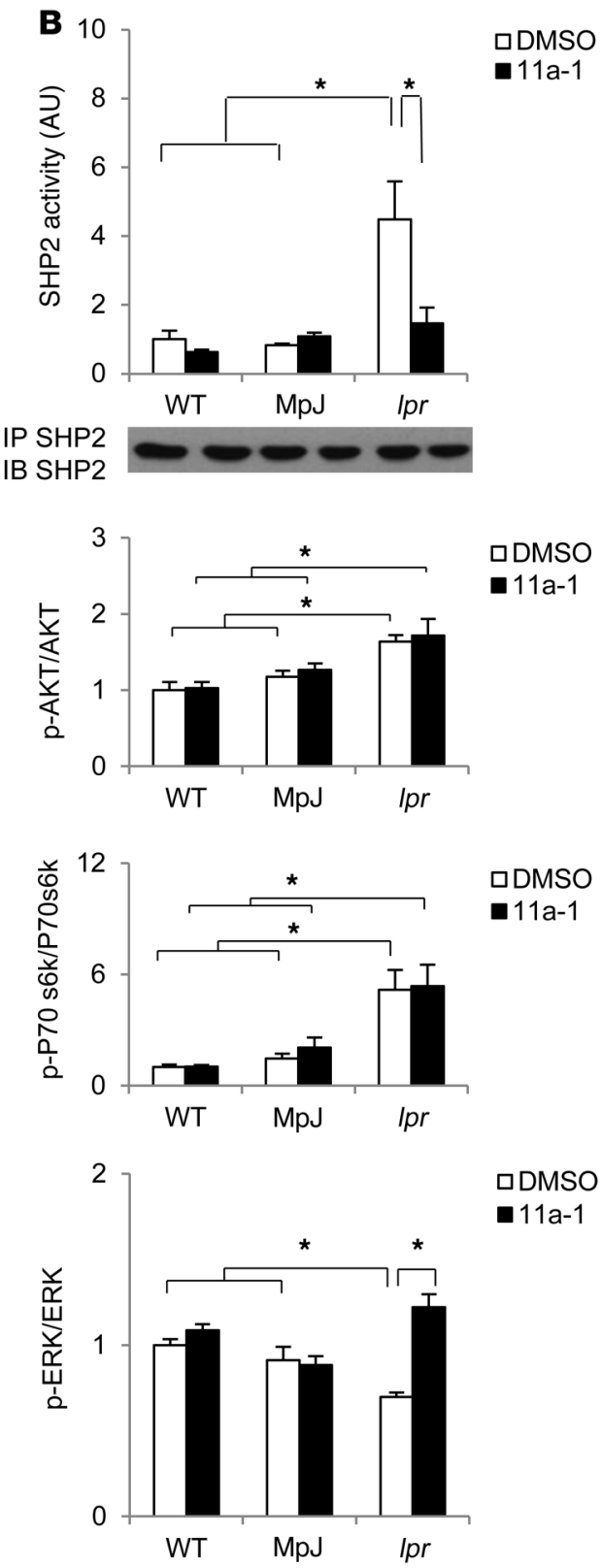

口DMSO

-11a-1
Figure 1. SHP2 activity is upregulated in both lupus patients and lupus-prone MRL/Ipr mice, the normalization of which reverses aberrant ERK/MAPK signaling.

(A) SHP2 immune complex PTP assays were conducted using pNPP as a substrate on human PBMC lysates and (B) mouse splenic lysates generated from 18-weekold control C57BL/6 WT, strain-control $\mathrm{MRL} / \mathrm{MpJ}$ (MpJ), and lupus-prone MRL//pr (Ipr) female mice that were either vehicle or SHP2 inhibitor (11a-1) treated (7.5 mg/ $\mathrm{kg} / \mathrm{d}$ ) for 6 weeks, starting at 12 weeks of age. Immunoblotting controls for levels of immunoprecipitated SHP2, showing comparable recovery, are shown below each figure. $n=6$ human samples/group and $n=3-8$ mice/group, respectively. Splenic lysates isolated from 18-week-old WT, $\mathrm{MpJ}$, and MRL/Ipr mice subjected to either vehicle or 11a-1 were immunoblotted with (C) anti-phospho-AKT and anti-phosphop70S6K or (D) anti-phospho-ERK, as indicated, followed by anti-AKT, anti-p70S6K, and anti-ERK, respectively, to control for loading. Parallel experimental samples were blotted with anti-SHP2 or antiGAPDH to determine expression levels of these proteins. Quantification of data ( $n=$ 3 mice/group) is shown to the right of each representative Western blot figure. Data represent mean $\pm \mathrm{SEM}$; ${ }^{*} P<0.05$, 1-way or 2-way ANOVA with Holm-Sidak post-test when ANOVA was significant.

of glomerulonephritis, proteinuria, and eventually, renal failure (41). To determine whether SHP2 activity is involved in SLE-mediated kidney dysfunction, we analyzed kidneys from 18-week-old WT, MRL/MpJ, and MRL/lpr female mice treated for 6 weeks with either vehicle or 11a-1. We observed that the MRL/lpr mice treated with SHP2 inhibitor had a nor- an SLE phenotype, we treated WT, MRL/MpJ, and MRL/lpr mice with either vehicle or 11a-1 for a period of 6 weeks, beginning at 12 weeks of age. MRL/lpr 11a-1-treated mice showed dramatically reduced skin lesions and had an overall healthier appearance, as compared with WT, MRL/MpJ, or vehicle-treated MRL/lpr mice (Figure 2A). Moreover, in response to the SHP2 inhibitor, spleens isolated from MRL/lpr mice were substantially decreased (Figure 2B), with lower spleen weights (Figure $2 \mathrm{C}$ ) and reduced total number of splenocytes (Figure 2D) as compared with MRL/lpr vehicle-treated spleens. No effects of the inhibitor were observed in spleens from WT or MRL/MpJ controls (Figure 2, B-D).

In addition to spleen, the kidney is also severely affected in SLE; as disease progresses, the kidney rapidly deteriorates, increasing mesangial cell proliferation, inducing vascular collapse, and enhancing $\mathrm{T}$ cell and immune complex accumulation (47). Together, this deterioration culminates in the onset malized appearance (Figure 2E), reduced kidney weight (Figure $2 \mathrm{~F}$ ), and a significant reduction in proteinuria (Figure $2 \mathrm{G}$ ), suggesting overall improved kidney function. Histologically, kidneys from MRL/lpr mice developed progressive crescentic glomerulonephritis, massive immune cell infiltration, and induced fibrosis (Figure 2H and Supplemental Figure 2, A and B), as compared with WT and MRL/MpJ controls. In contrast, treatment of $\mathrm{MRL} /$ pr mice with the SHP2 inhibitor prevented the progression of kidney disease in SLE-prone mice (Figure 2H and Supplemental Figure 2), suggesting that normalization of SHP2 activity ameliorates SLE-associated kidney damage.

Furthermore, treatment of the mice with the SHP2 inhibitor did not evoke unwarranted effects, as there was no weight loss or any other obvious adverse effect observed as a consequence of 11a-1 treatment (Figure 2I). Finally, Kaplan-Meier survival curves for $\mathrm{MRL} / \mathrm{lpr}$ mice treated with $11 \mathrm{a}-1$ ( $7.5 \mathrm{mg} / \mathrm{kg} / \mathrm{d})$ from 12 weeks to 
A

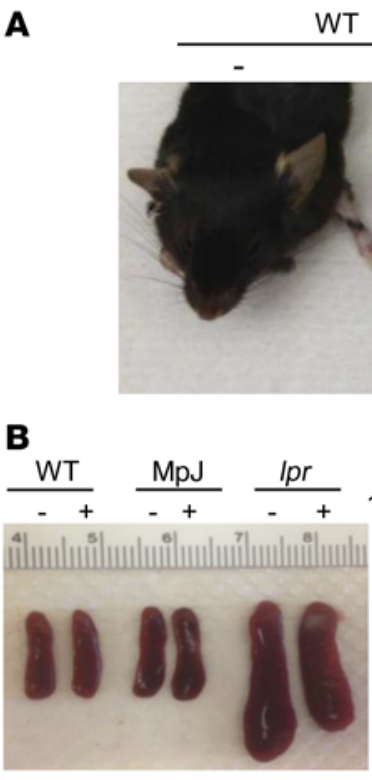

WT
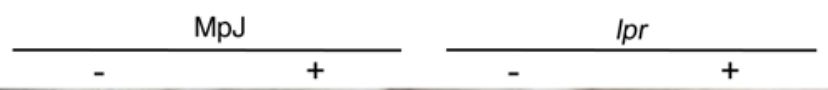

11a-1

E
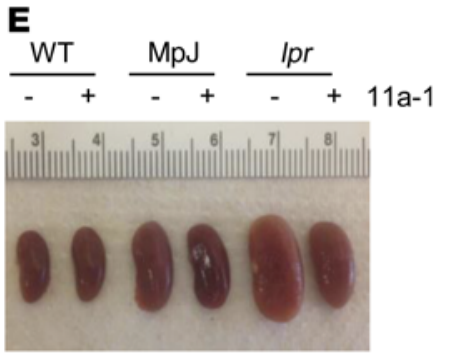

H

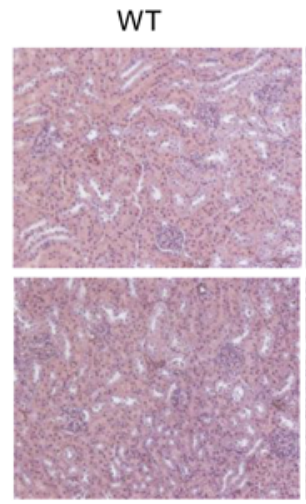

MpJ
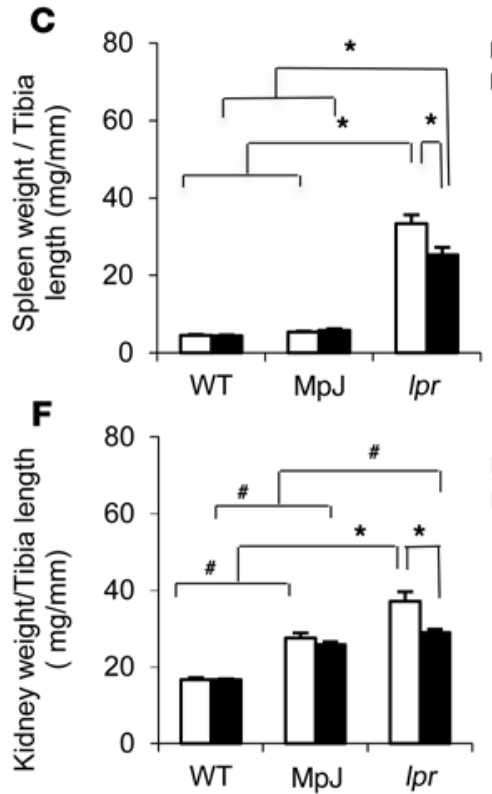

aDMSO

-11a-1

aDMSO

-11a-1

Ipr

DMSO

$11 \mathrm{a}-1$

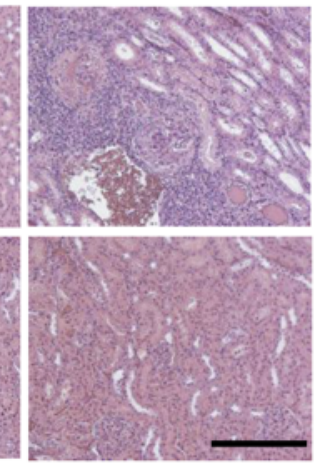

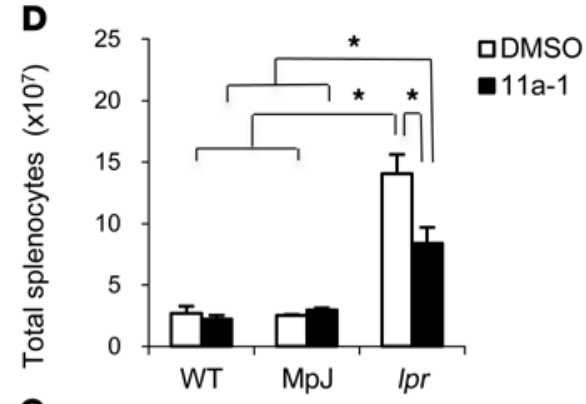

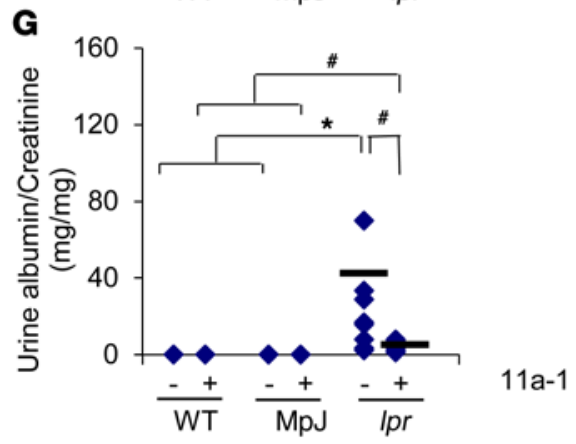

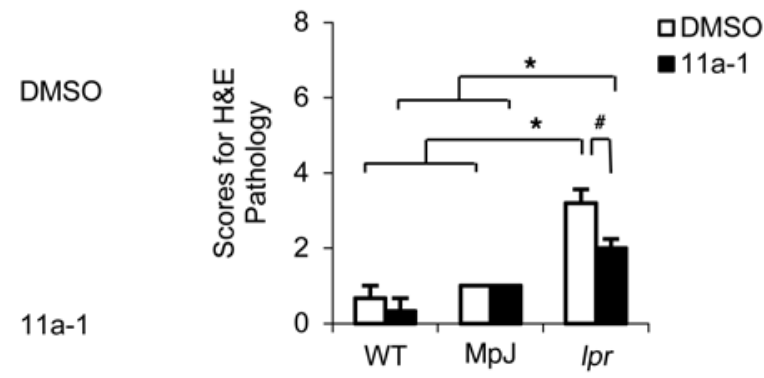

\section{I}

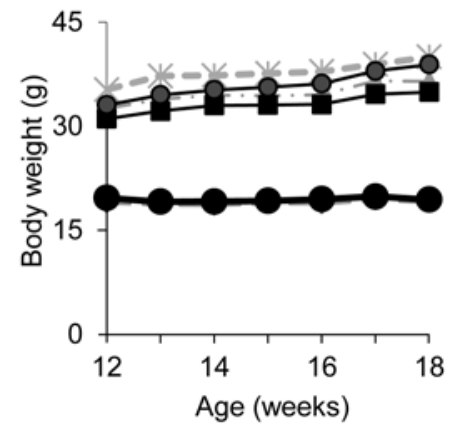

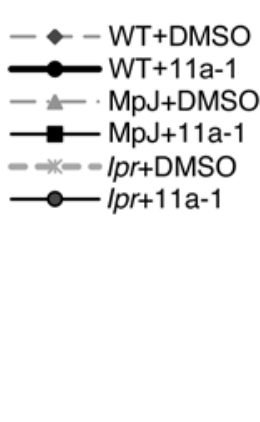

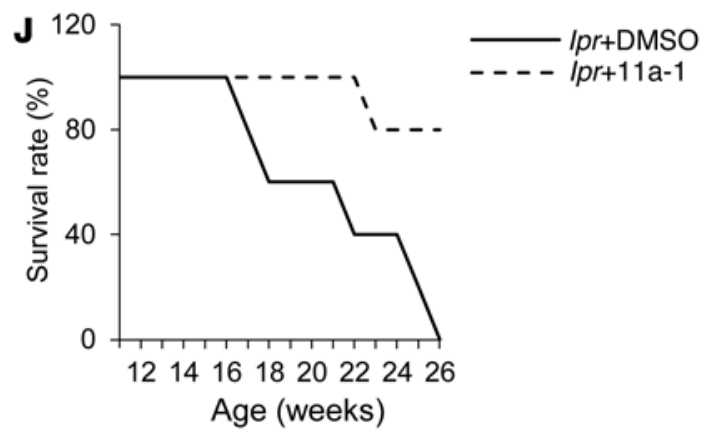


Figure 2. Inhibition of SHP2 activity reduces skin lesions, decreases splenomegaly, normalizes kidney structure and function, and prolongs MRL/lpr longevity. Representative photographs of (A) skin lesions or (B) spleens from WT, MpJ, and MRL/Ipr mice treated with vehicle or 11a-1 for 6 weeks. (C) Spleen weight to tibia length ratios ( $n=8$ mice/group) and (D) total splenocyte counts ( $n=3-5$ mice/group) from 18-week-old WT, MpJ, and MRL/Ipr female mice treated for 6 weeks with either vehicle or $11 \mathrm{a}-1(7.5 \mathrm{mg} / \mathrm{kg} / \mathrm{d})$. (E) Representative photograph of kidneys, (F) histograms showing kidney weight to tibia length ( $n=8$ mice/group), and (C) ratio of albumin to creatinine in urine ( $n=7-8$ mice per group), and (H) representative H\&E-stained kidney sections and pathological scores ( $n=4$ mice/group) from 18-week-old WT, MpJ, and MRL/lpr female mice treated for 6 weeks with vehicle or $11 \mathrm{a}-1$ (7.5 mg/kg/d). Scale bar: $500 \mu \mathrm{m}$. (I) Body weight measurements for 12- to 18-week-old WT, MpJ, and MRL/Ipr mice subjected to either vehicle or 11a-1 ( $n=8$ mice/group). (J) Kaplan-Meier survival curve in 12- to 26-week-old WT, MpJ, and MRL/Ipr mice subjected to either vehicle or 11a-1. $n=5$ mice/group. Note: all vehicle-treated MRL/Ipr mice died by 26 weeks, whereas only $20 \%$ of the 11a-1-treated mice died at that same time point. ${ }^{*} P<0.01$; ${ }^{\#} P<0.05$, where $P$ values were derived from 2-way ANOVA with Holm-Sidak post-test when ANOVA was significant.

26 weeks of age showed a remarkable improvement in survival rate of lupus-prone animals; more than $80 \%$ of $11 \mathrm{a}-1$-treated mice survived at a time point in which all vehicle-treated MRL/lpr mice had died (Figure 2J). Together, these data indicate that SHP2 activity is a positive mediator of SLE and that normalization of its activity prolongs life and ameliorates lupus pathogenicity in MRL/lpr mice.

SHP2 modulates the immune response in SLE. To measure the contribution of SHP2 activity on the immune response in SLE, we isolated whole blood immune cell subsets from vehicle- or 11a-1-treated WT, MRL/MpJ, and MRL/lprfemale mice. We found that the inhibitor reduced the elevated wbc count in the MRL/lpr mice (Figure 3A). No elevation or effects of 11a-1 treatment were observed in wbc isolated from WT or MRL/MpJ mice (Figure 3A). Moreover, no differences in rbc or platelet counts were observed in any these groups (Supplemental Figure 3A) with or without 11a-1 treatment, suggesting SLE does not play a significant role in altering these populations in these mice. Of the wbc population, only lymphocytes, but not neutrophils, monocytes, eosinophils, or basophils, were significantly decreased by 11a-1, even though the overall total numbers of neutrophils, monocytes, and eosinophils were each significantly elevated in MRL/lpr mice (Figure 3B and Supplemental Figure 3B). Furthermore, despite having no effect on the total percentage of circulating B cells $\left(\mathrm{CD} 45^{+} \mathrm{CD} 19^{+}\right)$ (Figure 3C and Supplemental Figure 3C), 11a-1 treatment reduced the total percentage of $\mathrm{T}$ cell lymphocytes $\left(\mathrm{CD} 45^{+} \mathrm{TCR} \alpha \beta^{+}\right)$in $\mathrm{MRL} / \mathrm{lpr}$ mice (Figure 3C and Supplemental Figure 3C). Indeed, of the circulating $\mathrm{T}$ cell subpopulations, SHP2 inhibition more selectively targeted $\mathrm{DN}$ T cells $\left(\mathrm{CD} 45^{+} \mathrm{CD} 4^{-} \mathrm{CD} 8^{-\mathrm{TCR}} \alpha \beta^{+}\right)$, with minimal effects observed in $\mathrm{CD}^{+}\left(\mathrm{CD} 45^{+} \mathrm{CD} 4^{+} \mathrm{CD} 8^{-} \mathrm{TCR} \alpha \beta^{+}\right)$or $\mathrm{CD}^{+}\left(\mathrm{CD} 45^{+} \mathrm{CD} 4^{-} \mathrm{CD} 8^{+} \mathrm{TCR} \alpha \beta^{+}\right) \mathrm{T}$ cells in $\mathrm{MRL} /$ lpr mice (Figure 3D and Supplemental Figure 3C), suggesting a positive role for SHP2 in modulating DN T cells specifically.

Decreasing SHP2 activity blocks abnormal T cell proliferation. To determine the mechanism by which SHP2 potentiates the abnormal immune response in SLE, we analyzed immune cell subsets in spleens isolated from 18-week-old vehicle- or 11a-1-treated WT, MRL/MpJ, or MRL/lpr female mice. Concomitant with the decrease in total splenocytes (Figure 2, B-D), we found that 11a-1 treatment significantly reduced the total number of $\mathrm{T}$ $\left(\mathrm{CD}^{+}\right)$cells (Figure 4, A and B), but not of B $\left(\mathrm{CD} 19^{+}\right)$cells (Figure 4, A and C) isolated from MRL/lpr spleens. Indeed, and in contrast, 11a-1 increased the total number of B cells in MRL/lpr spleens (Figure 4C), suggesting that inhibition of SHP2 may trigger a feedback mechanism to promote proliferation and/or expansion of these cells.

Next, we investigated the effects of SHP2 on T cell subsets and found reduced numbers of $\mathrm{CD}^{+}, \mathrm{CD}^{+}$, and DN T cells (Figure 4,
$\mathrm{D}$ and $\mathrm{E}$ ) in 11a-1-treated MRL/lpr spleens, as compared with WT, $\mathrm{MRL} / \mathrm{MpJ}$, and vehicle-treated controls, suggesting an inhibition of overall T cell-associated pathogenesis in these mice in the presence of the SHP2 inhibitor. Interestingly, no effects of SHP2 were observed on regulatory $\mathrm{T}\left(\mathrm{CD} 4^{+} \mathrm{CD} 25^{+}\right)$cells (Figure $4 \mathrm{E}$ and Supplemental Figure 4), suggesting that the decrease in $\mathrm{CD} 4^{+}, \mathrm{CD}^{+}$, and DN T cells is not mediated by indirect effects of the inhibitor on regulatory $\mathrm{T}$ cells, but rather by inhibition of SHP2 directly on $\mathrm{CD}^{+}, \mathrm{CD}^{+}$, and $\mathrm{DN} \mathrm{T}$ cell subsets.

To confirm whether these effects are a direct consequence of SHP2's involvement in T cell proliferation, we isolated and cultured $\mathrm{T}$ cells from splenocytes for 48 hours in the presence of either vehicle or 11a-1 and either in the absence or presence of antibodies directed against CD3 and CD28 (anti-CD3 and -CD28). Proliferation of both naive and activated $\mathrm{T}$ cells was significantly inhibited in the MRL/lpr 11a-1-treated cells, whereas no effects of the inhibitor were observed in WT or MRL/MpJ control cells, both in the presence and absence of activating antibodies (Figure $4 \mathrm{~F}$ ). Importantly, SHP2 was necessary for proliferation specifically, as no effects on viability were observed in either MRL/lpr vehicleor inhibitor-treated splenocyte $\mathrm{T}$ cells, either in the presence or absence of activating antibodies (Figure $4 \mathrm{G}$ ).

To further assess the SHP2-dependent cellular immune responses in tissues, we used flow cytometry to measure $\mathrm{T}$ cell, macrophage, and neutrophil infiltration in kidneys of vehicle- and inhibitor-treated MRL/lpr female mice. As in immune cell subsets isolated from spleen (Figure 4), the SHP2 inhibitor reduced the overall number of leukocytes (CD45 $5^{+}$cells) (Supplemental Figure $5 \mathrm{~A})$, specifically targeting infiltration of $\mathrm{T}$ cells $\left(\mathrm{CD} 45^{+} \mathrm{CD} 3^{+}\right)$ (Supplemental Figure 5B) and reducing the overall number of all $\mathrm{CD}^{+}, \mathrm{CD}^{+}$, and DN T cells (Supplemental Figure 5C). In addition, we observed a significant reduction in infiltrating macrophages $\left(\mathrm{CD}^{4} 5^{+} \mathrm{CD}^{-} \mathrm{CD}^{-} 1 \mathrm{~b}^{+} \mathrm{Ly}^{6} \mathrm{G}^{-}\right)$and neutrophils $\left(\mathrm{CD} 45^{+} \mathrm{CD} 3^{-}\right.$ CD $11 b^{+}{\text {Ly } 6 G^{+}}^{+}$in inhibitor-treated SLE kidneys (Supplemental Figure 5D). Taken together, these data suggest that 11a-1 treatment may prevent the migration of $\mathrm{T}$ cells and inflammatory cells into SLE-targeted organs such as the spleen and kidney.

$S H P 2$ signaling modulates DN T cell proliferation in SLE. We previously found that only DN T cells were affected by the SHP2 inhibitor in whole blood, suggesting that this cell subtype is more sensitive to SHP2 regulation in SLE (Figure 3D). Moreover, while autoreactive DN T cells are not typical in a normal individual's circulation, they can be produced by $\mathrm{CD}^{+} \mathrm{T}$ cells in $\operatorname{SLE}$ patients $(48,49)$ and are likely implicated in the pathogenesis of both SLE patients (50) and $\mathrm{MRL} / \mathrm{pr}$ mice (5). Therefore, to examine the mechanism of regulation of SHP2 specifically in these cells, we isolated and cultured DN T cells from the lymph nodes of 18 -week-old MRL/lpr female 
A

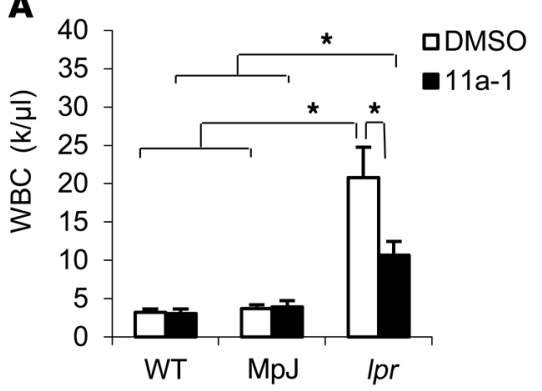

C

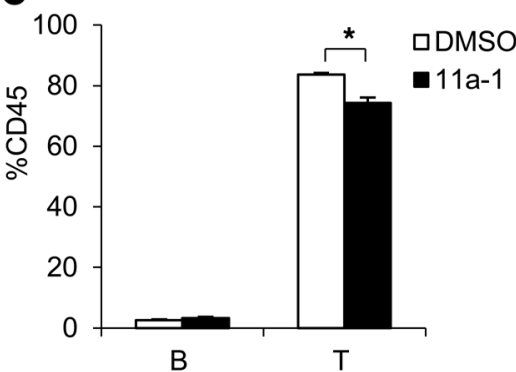

B

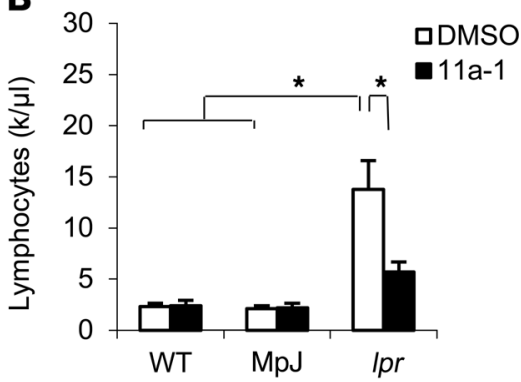

D

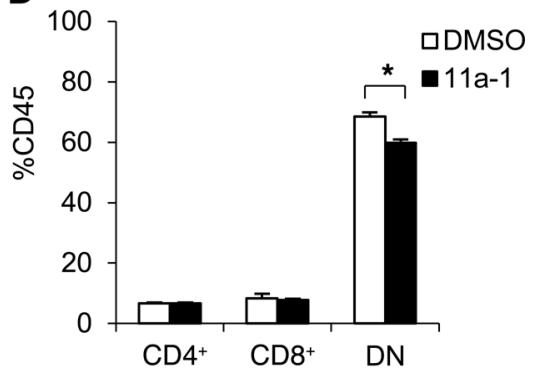

Figure 3. Inhibition of SHP2 reduces the number of circulating DN T cells in peripheral blood of MRL/lpr mice. Total number of circulating (A) wbc and (B) lymphocytes in peripheral blood of 18-week-old WT, $\mathrm{MpJ}$, and MRL/Ipr female mice treated for 6 weeks with vehicle or $11 \mathrm{a}-1$ ( $7.5 \mathrm{mg} / \mathrm{kg} / \mathrm{d}) . n=7$ mice/group. Peripheral blood from 18-week-old MRL/Ipr female mice treated with vehicle or 11a-1 for 6 weeks was collected to determine percentage of (C) B and T cells and (D) various $T$ cell subsets, including CD3 ${ }^{+} \mathrm{CD} 4{ }^{+} \mathrm{CD} 8-\mathrm{TCR} \alpha \beta^{+}\left(\mathrm{CD} 4^{+}\right)$, $\mathrm{CD}^{+}{ }^{+} \mathrm{CD} 4^{-}{ }^{-C D} 8^{+}{ }^{+} \mathrm{CR} \alpha \beta^{+}\left(\mathrm{CD} 8^{+}\right)$, and CD3 ${ }^{+} \mathrm{CD} 4-\mathrm{CD} 8^{-} \mathrm{TCR} \alpha \beta^{+}$ (DN) T cells in CD45 leukocytes. $n=4$ mice/group. ${ }^{*} P$ $<0.05$, 2-way ANOVA with Holm-Sidak post-test when ANOVA was significant.

Here, we found that activated cells had significantly increased levels of IL-17A/F (Figure 6C) and IFN- $\gamma$ (Figure 6D), as compared with nonactivated controls. These cytokines were also significantly reduced following treatment with 11a-1 (Figure 6, C and D), suggesting a functional role for SHP2 in mediating the production of IFN- $\gamma$ and IL-17A/F by DN T cells in SLE. To further val-

mice. Cells were activated with anti-CD3 and anti-CD28 antibodies and were then cultured with either vehicle or 11a-1 for 48 hours. While the use of the SHP2 inhibitor had no significant effects on AKT or pS6RP activities in MRL/lpr DN T cells (Figure 5A), ERK/ MAPK activation was increased (Figure 5B), consistent with effects observed in spleen lysates ex vivo (Figure 1). Moreover, proliferation of MRL/lpr DN T cells was reduced by inhibitor treatment, both at baseline and in response to antibody activation, as compared with vehicle-treated MRL/lpr cells (Figure $5 \mathrm{C}$ ). Importantly, this decrease in the total number of DN T cells was not a consequence of reduced viability, as this remained unaffected between vehicleand inhibitor-treated groups, both in the presence and absence of CD3 and CD28 antibodies (Figure 5D) and consistent with effects observed in splenocytes (Figure 4, F and G). Together, these data suggest that a mechanism of regulation by SHP2 in SLE is to promote DN T cell proliferation.

SHP2 activity induces production of a specific subset of cytokines in SLE. Aberrant regulation of cytokines, such as IL-6, IL17A/A homodimer, type II IFN- $\gamma$, and TNF- $\alpha$, is closely linked to pathogenesis of SLE, playing key roles in the regulation of systemic inflammation, local tissue damage, and immunomodulation (51-62). To determine whether SHP2 activity is involved in modulating cytokine production in SLE, we collected serum from either vehicle- or inhibitor-treated WT, MRL/MpJ, and MRL/lpr mice and measured circulating concentrations of IFN- $\gamma$, TNF- $\alpha$, IL-17A/A, IL-17A/F, and IL-6. Despite significant upregulation of multiple cytokines in MRL/lpr mice, as compared with WT and MRL/MpJ mice (Supplemental Figure 6), treatment of the SLEprone mice with $11 \mathrm{a}-1$ only reduced the production of IL-17A/F heterodimer (Figure 6A) and IFN- $\gamma$ (Figure 6B). No significant differences in TNF- $\alpha$, IL-17A/A homodimer, or IL- 6 were observed between vehicle- and inhibitor-treated SLE-derived serum samples (Supplemental Figure 6). Further, this result was validated in DN T cells isolated from MRL/lpr lymph nodes and cultured for 120 hours in the presence of activating antibodies CD3 and CD28. idate these findings, we found that the degree of kidney dysfunction in MRL/lpr mice directly correlated with induced serological levels of both IL-17A/F (Figure 6E) and IFN- $\gamma$ (Figure 6F), validating the pathogenic properties of these cytokines in SLE.

SHP2 activity is not involved in autoantibody production. In its early stages, SLE is characterized by generalized B cell activation, autoreactive $B$ cell expansion, and hypergammaglobulinemia, all of which induce DNA-specific autoantibody production (41). To determine whether SHP2, in addition to T cell function, is involved in B cell regulation of SLE, we measured levels of autoantibody production in serum derived from vehicle- or 11a-1-treated WT, MRL/MpJ, and MRL/lpr female mice. Levels of anti-dsDNA and total IgG antibodies were not reduced in response to SHP2 inhibitor treatment in MRL/lpr mice (Figure 7, A and B) despite the increase in total B cell numbers in MRL/lpr splenocytes (Figure 4C), suggesting SHP2 does not affect $B$ cell function in SLE. This finding was further validated by measuring the numbers of MRL/lpr spleen extrafollicular T helper cells (TCR ${ }^{+}{ }^{+} \mathrm{CD} 4^{+}{ }^{+}$SGL1-CD62L-) (Figure $7 \mathrm{C}$ ), plasmablasts (TCR $\beta^{-} \mathrm{CD} 44^{\text {hi }} \mathrm{B}^{2} 2 \mathrm{O}^{+} \mathrm{CD} 138^{+}$) (Figure $7 \mathrm{D}$ ), and plasma cells (TCR $\beta^{-} \mathrm{CD} 44^{\text {hi }} B 220^{-} \mathrm{CD} 138^{+}$) (Figure $7 \mathrm{D}$ ), which are each induced to help mediate production of autoantibodies. Here, both vehicleand 11a-1-treated MRL/lpr spleens showed similar cell numbers of these populations, confirming that $\mathrm{B}$ cell function is unaffected and independent of SHP2 activity in SLE (Figure 7, C and D).

SHP2 activity is involved in human SLE, inducing $T$ cell proliferation and increasing production of IFN- $\gamma$ and IL-17 A/F. To determine the clinical relevance of our findings, we measured serological levels of IL-17A/F and IFN- $\gamma$ from disease-active SLE patients. We found that both IL-17A/F (Figure 8A) and IFN- $\gamma$ (Figure 8B) were significantly increased in SLE patients. Next, we cultured T cells isolated from human SLE patient PBMCs, either in the presence or absence of anti-CD3 and anti-CD28 antibodies, for 48 hours. T cells derived from lupus patients had increased clonal expansion (Figure $8 \mathrm{C}$ ) and significantly increased proliferation after only 48 hours in culture (Fig- 
A
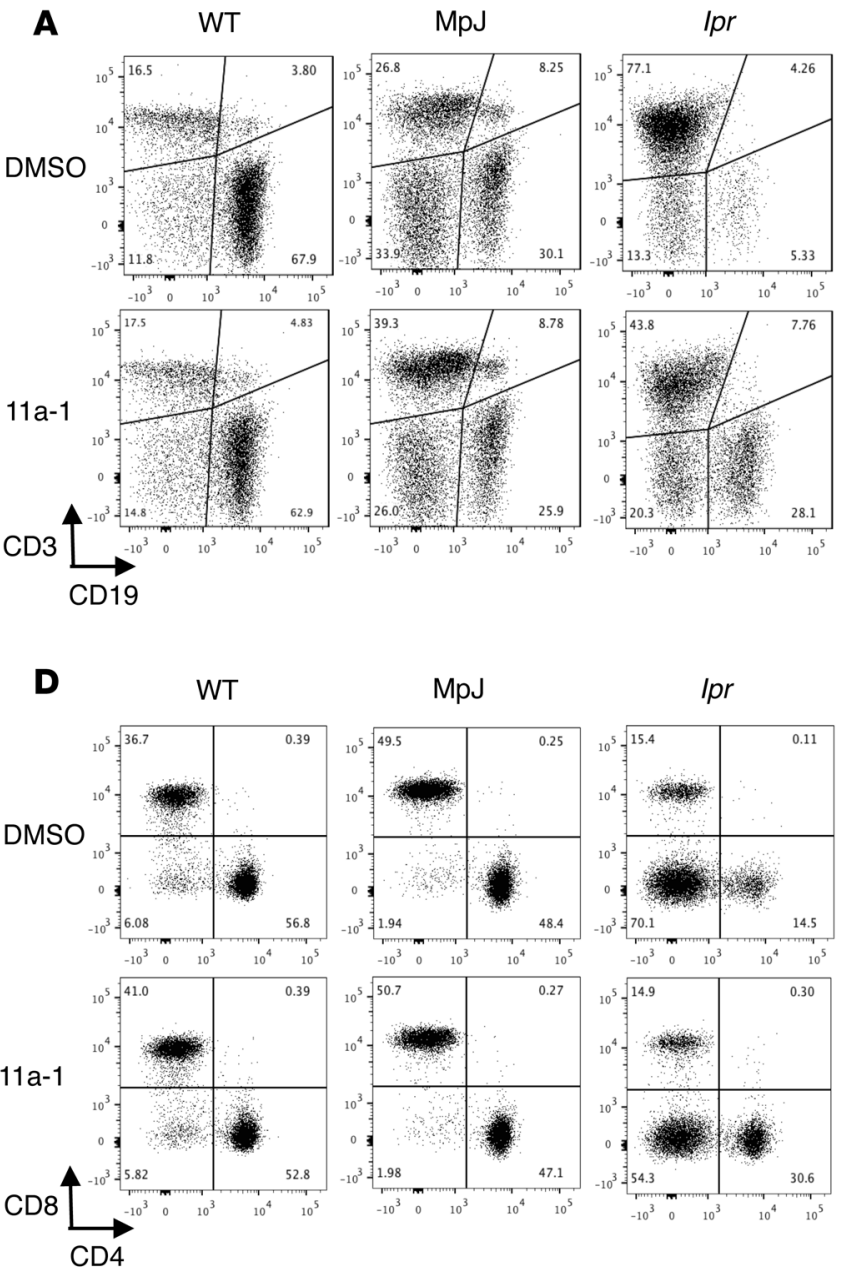

F

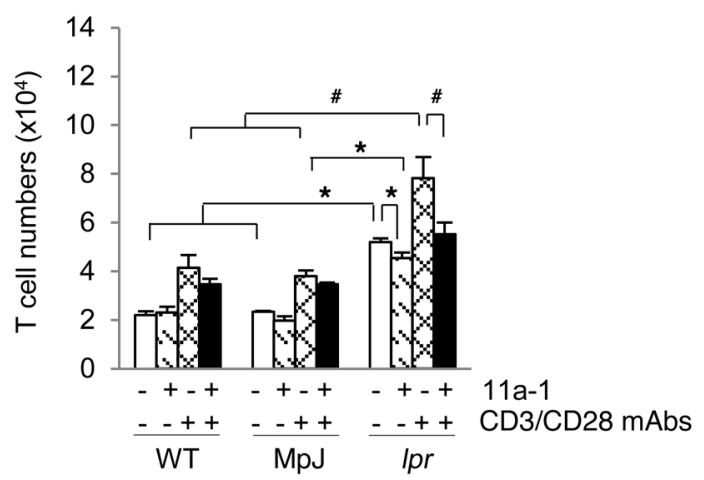

G
B

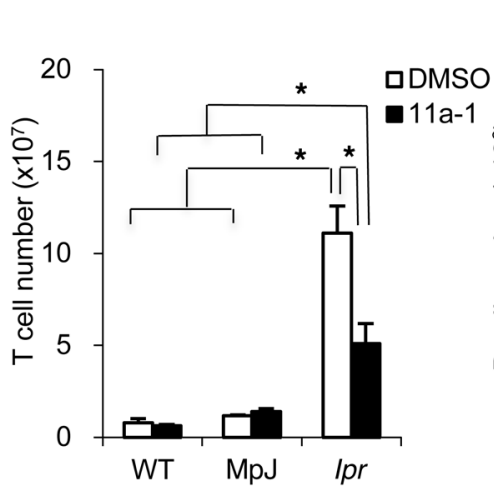

C

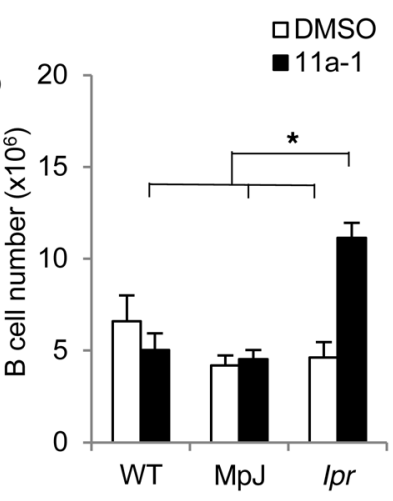

E

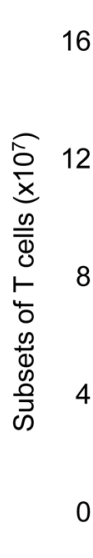

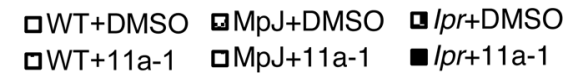
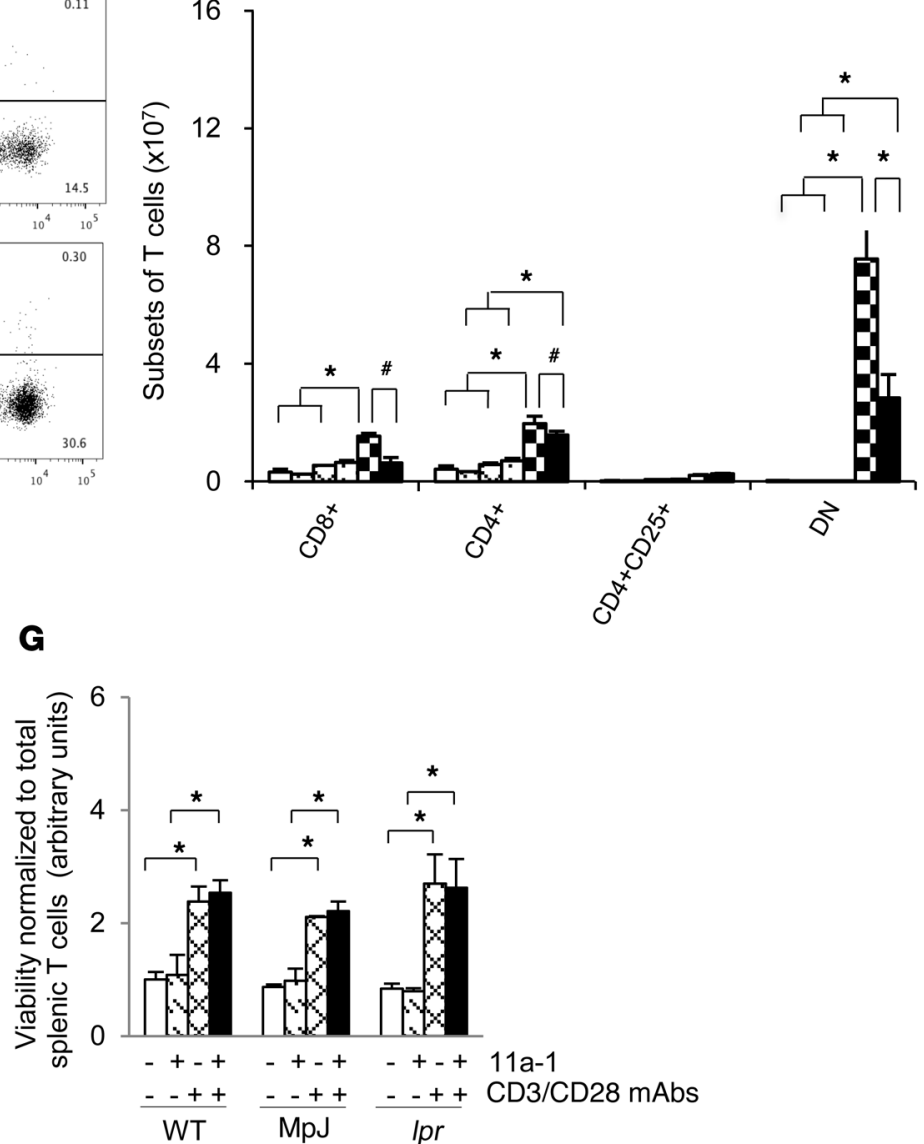

Figure 4. Normalization of SHP2 activity reduces T cell proliferation in MRL/Ipr spleens. (A) Representative flow cytometry of T cells (CD3+) and B cells (CD19') isolated from spleens of 18-week-old WT, MpJ, and MRL/Ipr female mice treated for 6 weeks with vehicle or 11a-1 (7.5 mg/kg/d). Quantification of the total number of (B) T cells and (C) B cells isolated from MRL/Ipr spleens. $n=3-5$ mice/group. (D) Representative flow cytometry of CD ${ }^{+}$gated T cells to identify T cell subsets: $\mathrm{CD}^{+}, \mathrm{CD}^{+}$, and CD4-CD8- cells in spleens from 18-week-old WT, MpJ, and MRL/Ipr female treated with vehicle or 11a-1 for 6 weeks. (E) Quantification of T cell subsets in WT, MpJ, and MRL/lpr mouse spleens. $n=3-5$ mice/group. T cells isolated from spleens of 18-week-old WT, $\mathrm{MpJ}$, and MRL/Ipr mice were cultured $\left(1 \times 10^{5}\right.$ cells/well) in 96-well plates for 48 hours in the presence of vehicle (DMSO) or $11 \mathrm{a}-1$ (10 $\left.\mu \mathrm{g} / \mathrm{ml}\right)$ and either in the presence or absence of T cell-activating antibodies CD3 and CD28 to determine (F) proliferation (change in total number of cells) and (C) viability (measure of cell death). $n=3$ independent experiments. ${ }^{*} P<0.01$; ${ }^{*} P<0.05$, 2-way ANOVA with Holm-Sidak post-test when ANOVA was significant. 
A

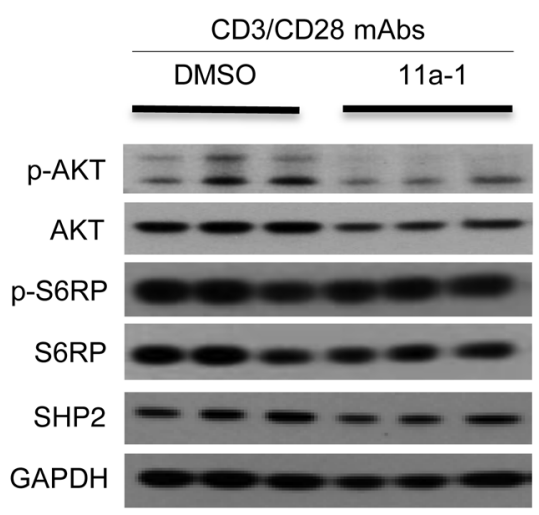

B

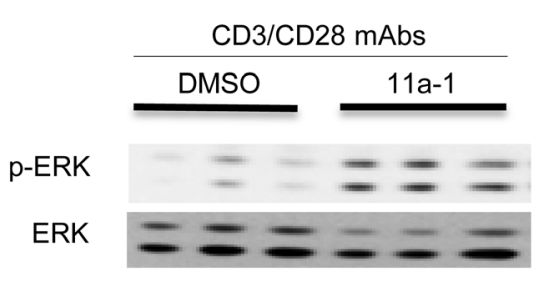

C

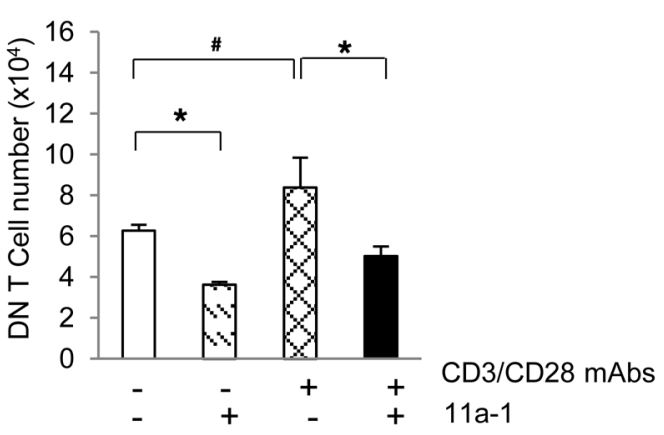

ure 8D), as compared with normal patient samples (Figure 8, C and D). Conversely, $\mathrm{T}$ cells derived from lupus patients treated with the SHP2 inhibitor showed reduced clonal expansion (Figure $8 \mathrm{C}$ ) and significantly decreased $\mathrm{T}$ cell proliferation (Figure 8D). No differences in viability were observed between vehicle and SLE inhibitor-treated cells either in the absence or presence of inhibitor (Figure 8E), suggesting that SHP2 functions to specifically target abnormal $\mathrm{T}$ cell proliferation in SLE. No aberrant effects were observed in normal patient cells in response to inhibitor treatment, suggesting minimal off-target effects in human cells (Figure 8C).

Concomitant to the cytokine levels observed in patient serum, cultured $\mathrm{T}$ cells isolated from SLE patients also showed higher levels of IL-17A/F (Figure 8F) and IFN- $\gamma$ (Figure 8G) in response to T cell activation, as compared with normal patients. The expression of
Figure 5. SHP2 activity specifically modulates DN T cell proliferation to promote aberrant ERK/MAPK, but not AKT/mTOR, signaling in this immune cell subset. DN T cells isolated from lymph nodes of 18 -week-old $\mathrm{MRL} / / \mathrm{pr}$ mice were cultured $\left(3 \times 10^{6}\right.$ cells/well) in 6-well plates for 48 hours in the presence of vehicle (DMSO) or $11 \mathrm{a}-1(10 \mu \mathrm{g} / \mathrm{ml})$ as well as T cell-activating antibodies anti-CD3 and anti-CD28. Cells were then harvested, lysed, and immunoblotted with (A) anti-phospho-AKT and anti-phospho-S6RP and (B) anti-phospho-ERK, as indicated, followed by anti-AKT, anti-S6RP, anti-SHP2, anti-GAPDH, and anti-ERK, respectively, to control for loading and protein expression levels. Quantification of Western blots from $n=3$ independent experiments represents the mean $\pm \mathrm{SEM}$. DN T cells isolated from lymph nodes of 18 -week-old MRL//pr mice were cultured ( $1 \times$ $10^{5}$ cells/well) in 96-well plates for 48 hours with either vehicle (DMSO) or 11a-1 $(10 \mu \mathrm{g} / \mathrm{ml})$ and in the presence or absence of T cell-activating antibodies anti-CD3 and anti-CD28 and were assessed for (C) proliferation or (D) viability. $n=3$ independent experiments. ${ }^{*} P<0.01$; ${ }^{*} P<$ 0.05 , 1-way or 2-way ANOVA with Holm-Sidak post-test when ANOVA was significant. these cytokines was significantly reduced following treatment with 11a-1 (Figure 8, F and G), further suggesting that the pathogenesis of SLE may directly be correlated to the expression of these cytokines.

\section{Discussion}

There is no cure for lupus, a disease that can be fatal. Moreover, development of novel, disease-specific, and side effect-free drugs for SLE have met unprecedented obstacles (63). Here, our data are the first, to our knowledge, to suggest that increased SHP2 activity and the aberrant effects this has on disease-active $\mathrm{T}$ cell proliferation and downstream cytokine production are integral to the molecular and pathophysiological effects of SLE. Furthermore, use of a potent SHP2 inhibitor reversed the deleterious effects of SLE-associated organ damage, confirming the marked impact that increased activity of this enzyme has on SLE etiology. Taken 

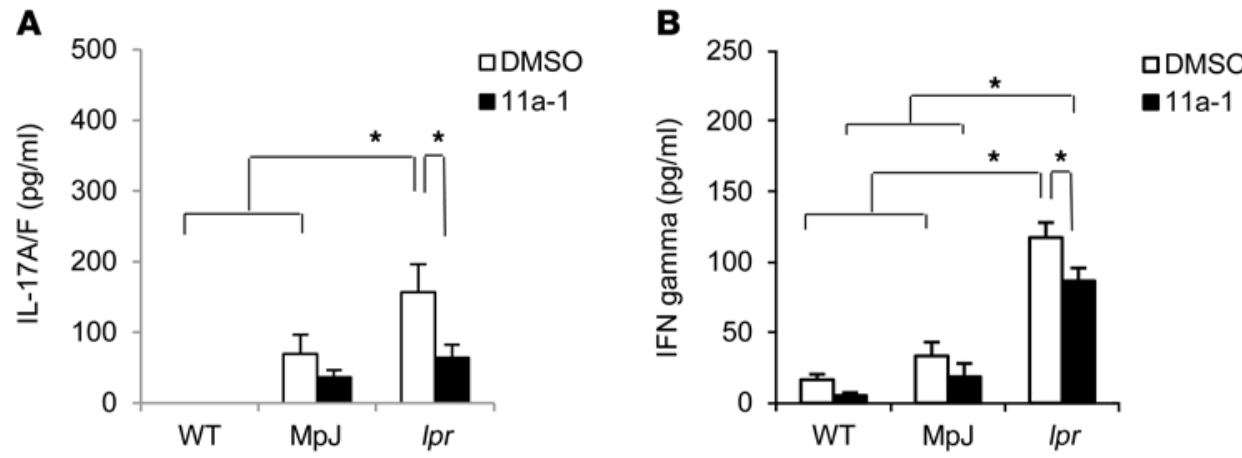

Figure 6. SHP2 activity mediates production of a specific subset of cytokines, IFN- $\gamma$, and IL-17A/F heterodimers in SLE. Serum from 18-week-old WT, MpJ, and MRL/Ipr female mice treated for 6 weeks with vehicle or $11 \mathrm{a}-1$ ( $7.5 \mathrm{mg} / \mathrm{kg} / \mathrm{d})$ was collected and assessed for levels of (A) IL-17A/F or (B) IFN- $\gamma \cdot n=3-8$ mice/ group. DN T cells were isolated from MRL/Ipr mouse lymph nodes and cultured for 120 hours in the presence or absence of anti-CD3 and anti-CD28 antibodies and with either vehicle or

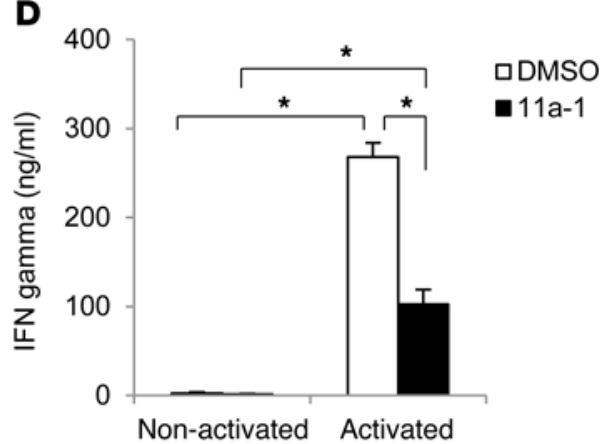
11a-1. These were assessed for levels

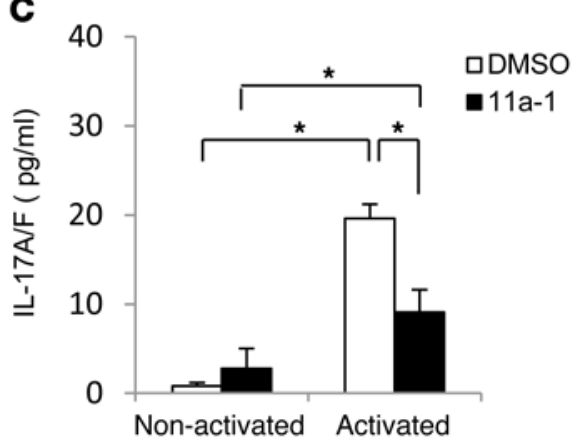
of (C) IL-17A/F and (D) IFN- $\gamma . n=3$ independent experiments. Pearson correlation analysis showing relationship of kidney dysfunction relative to the expression of serum cytokines (E) IL-17A/F and (F) IFN- $\gamma$ from WT, MpJ, and MRL/Ipr mice, treated with either vehicle or 11a-1 for 6 weeks. $n=30$. ${ }^{*} P$ $<0.01$; ${ }^{\#} P<0.05$, 2-way ANOVA with Holm-Sidak post-test when ANOVA was significant.
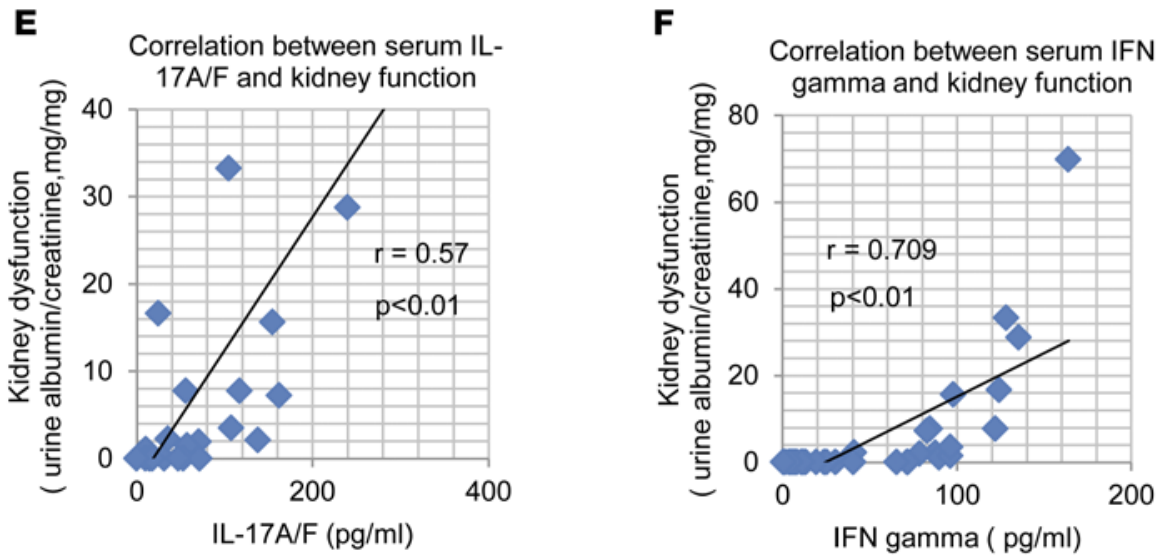

together, our data provide compelling evidence to suggest that targeted inhibition of SHP2 activity may be a potent, novel, and specific therapy for treatment of patients with SLE.

SHP2 is a ubiquitously expressed protein tyrosine phosphatase that modulates nearly all cytokine, integrin, and tyrosine receptor signaling pathways. It also appears to have a causal genetic link to SLE and other autoimmune-like disorders; indeed, more than 50 patients with NS, an autosomal dominant disorder principally caused by GOF SHP2 mutations, have been subsequently diagnosed with SLE (30-35). Additionally, NS mice (SHP2 ${ }^{\mathrm{D} 61 \mathrm{G} /+}$ ) develop splenomegaly, have increased neutrophils and leukocytes, and develop an autoimmune-like disease (26). Mechanistically, SHP2 is required for T cell development and function, including in differentiation, proliferation, and migration of these cells $(64,65)$. Specifically, Lck-Cre-mediated deletion of SHP2 in the thymus results in a significant block in thymocyte proliferation and differentiation, implicating SHP2 as a positive regulator of $\mathrm{T}$ cell development and function (64). Specific involvement for SHP2 in these processes has also been documented; use of a different SHP2 inhibitor (NSC-87877) in response to experimental autoimmune encephalomyelitis (EAE), an induced autoimmune response, showed resistance to the induction of the disease (65). Importantly, T cell-conditional SHP2-deficient mice treated with this drug are no longer resistant to EAE, suggesting that inhibition of SHP2 directly contributes to the amelioration of the autoimmune response (65).

Because of its critical role in inflammation, we hypothesized that SHP2 could be an integral mediator of SLE pathogenesis. Indeed, SHP2 has an already established role as an important regulator of inhibitory receptor tyrosine kinase signaling in immune cells. Specifically, SHP2 is recruited to the cytoplasmic tail of cytotoxic T lymphocyte-associated antigen 4 (CTLA-4), programmed death-1 (PD-1), B and T lymphocyte attenuator (BTLA), killer cell Ig-like receptors (KIRs), and CD31 (PECAM-1) in lymphocytes (66-68), likely to mediate dephosphorylation and inactivation of these immunoregulatory receptors. Importantly, the effects of receptor inactivation can be profound. CTLA-4-deficient mice develop severe systemic lymphoproliferative disease and die 
A
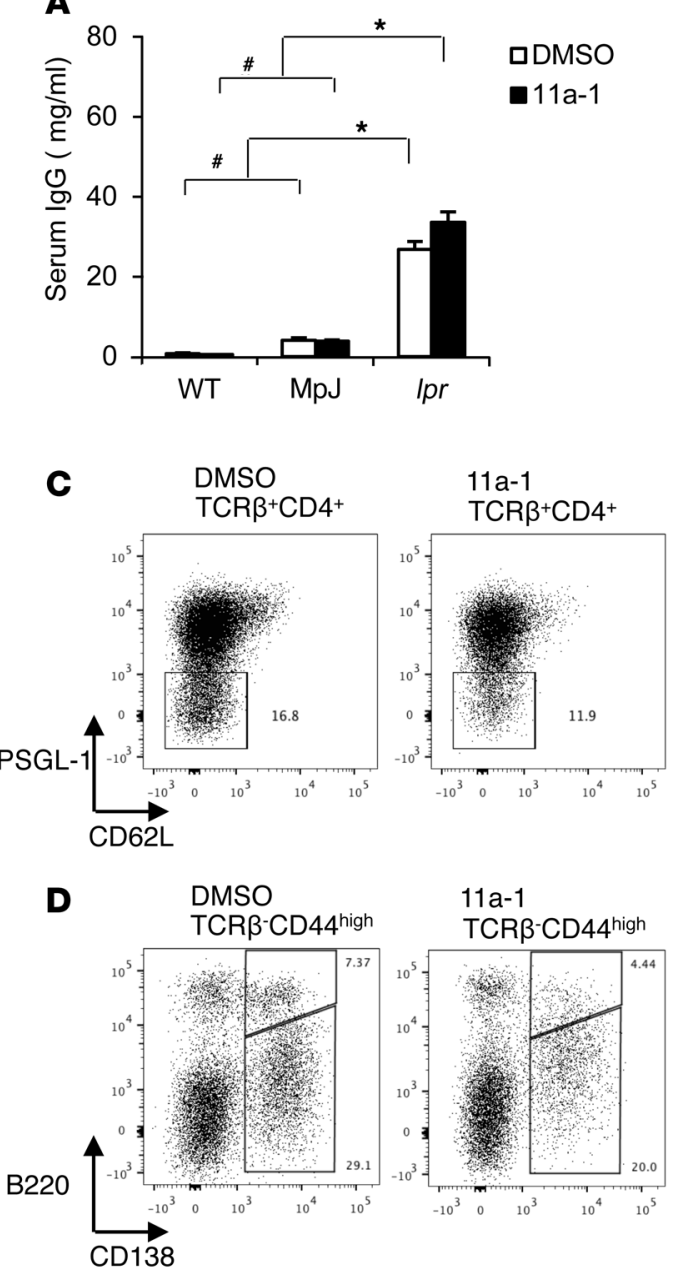

B
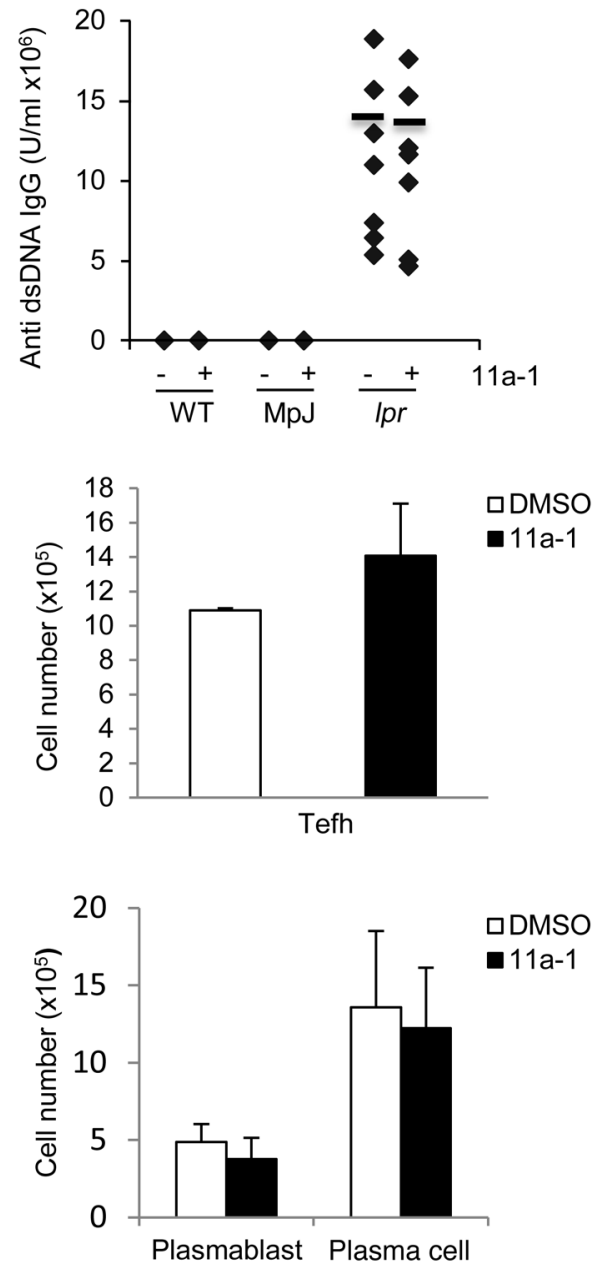

Figure 7. SHP2 activity is not involved in autoantibody production. (A) Serum IgG and (B) anti-dsDNA IgG were measured in 18-week-old WT, MpJ, and MRL/Ipr female mice treated for 6 weeks with vehicle or $11 \mathrm{a}-1$ (7.5 mg/kg/d) $n=7-8$ mice/group. Representative flow cytometry and corresponding quantification of (C) extrafollicular T helper cells (Tefh) (TCR $\beta{ }^{+}$CD4 ${ }^{+}$PSCL-1 CD62 $\left.\mathrm{L}^{-}\right)$and (D) plasmoblasts (TCR $\beta-C D 44^{\text {hi }} B 220^{+}$CD138+) and plasma cells (TCR $\beta$ CD44 ${ }^{\text {hi }}$ B220-(D138+) isolated from spleens of 18-week-old WT, MpJ, and MRL/Ipr female mice treated for 6 weeks with vehicle or $11 \mathrm{a}-1$ ( $7.5 \mathrm{mg} / \mathrm{kg} / \mathrm{d})$. $n=3-5$ mice/group. ${ }^{*} P<0.01$; ${ }^{\#} P<0.05$, 2-way ANOVA with Holm-Sidak post-test when ANOVA was significant. within 3 to 4 weeks after birth $(69,70)$. PD-1-deficient mice on a C57BL/6 background develop late-onset progressive arthritis and lupus-like glomerulonephritis (71), and mice on a BALB/c background develop autoimmune cardiomyopathy (72). Therefore, SHP2-mediated inactivation of immunoregulatory receptors may contribute to the development of the autoimmune-like phenotypes described above.

Differential pathways modulate activation of specific immune subsets, the aberrant regulation of which may promote concordant SLE-associated organ damage and disease. However, the cellular and mechanistic complexities of these effects in SLE remain unclear. In this regard, involvement of ERK/MAPK and PI3K/ AKT/mTOR signaling has been implicated in SLE. Specifically, ERK activity is decreased in lupus, and this defective signaling causes abnormal $\mathrm{T}$ cell epigenetic homeostasis, DNA methylation, loss of self tolerance, abnormal cytokine production, acquisition of cytotoxic responses, and ultimately, development of autoimmunity $(45,46)$. Indeed, T cells treated with ERK/MAPK pathway inhibitors become autoreactive in vitro and induce autoimmunity in vivo $(43,73,74)$. Decreased ERK signaling in T cells alone also causes a lupus-like phenotype in mice, reducing DNA methyltransferase 1 (DNMT1) expression, inducing DNA hypomethylation and overexpression of methylation-sensitive genes and leading to autoreactivity and autoimmunity (73). Similarly, T cells isolated from patients with lupus or treated with the lupus-inducing drug hydralazine show that DNA methylation is inhibited and DNMT1 expression is decreased $(43,73)$. Our data further support these findings and suggest that the regulation of ERK may be modulated either directly or indirectly through modulation of the epigenetic effects of gene expression by SHP2 $(43,44)$. Indeed, since ERK/ MAPK activity appears to be tissue or cell specific (26), further investigation is required to determine the precise mechanism or mechanisms by which SHP2 modulates this pathway in SLE.

Unlike ERK/MAPK activity, PI3K/AKT/mTOR activity is increased in SLE-prone MRL/lpr mice as well as in human lupus patients $(41,75)$. PI3K expression exists broadly in immune cells, including T cells, B cells, monocytes, macrophages, neutrophils, and dendritic cells. As such, PI3K inhibitors or deletion of PI3K reduces the chemotactic response of these cell types in both in vitro and in vivo migration assays (76). Inhibition of PI3K/AKT signaling also ameliorates lupus pathogenicity, as demonstrated by a reduction in proteinuria and improvement in the histological assessment of the kidney (77). However, inhibition principally targets $\mathrm{B}$ cells and $\mathrm{CD} 4^{+}$memory $\mathrm{T}$ cells, leading to decreased production of TNF- $\alpha$ and IL- 6 and reduced B cell expansion and production of autoantibodies $(38,41,77)$. In contrast, while our data 


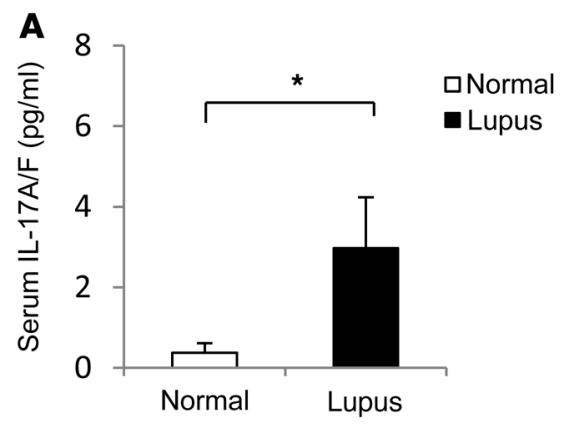

C
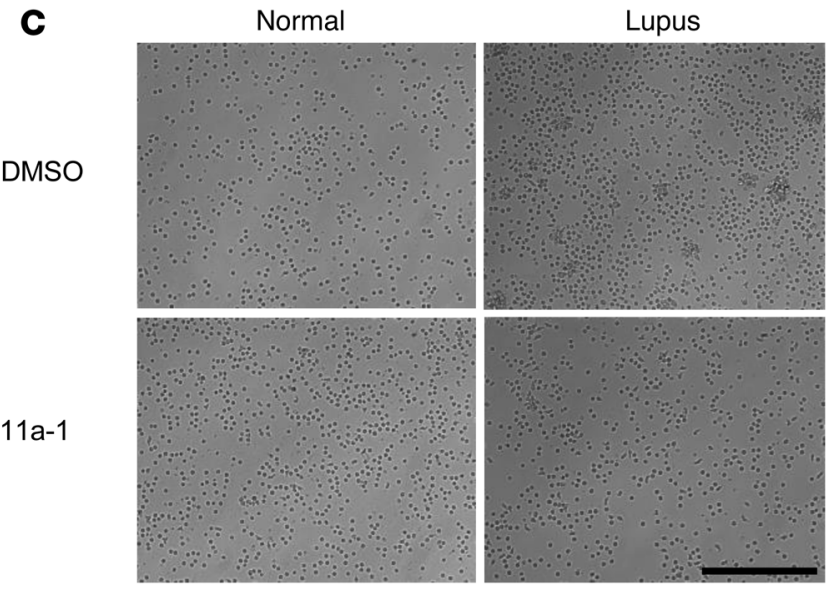

B

DMSO

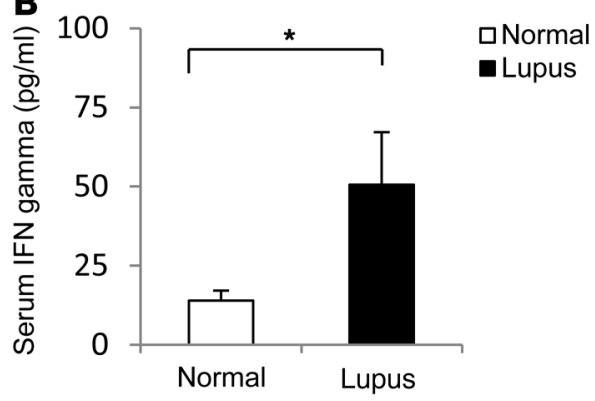

D
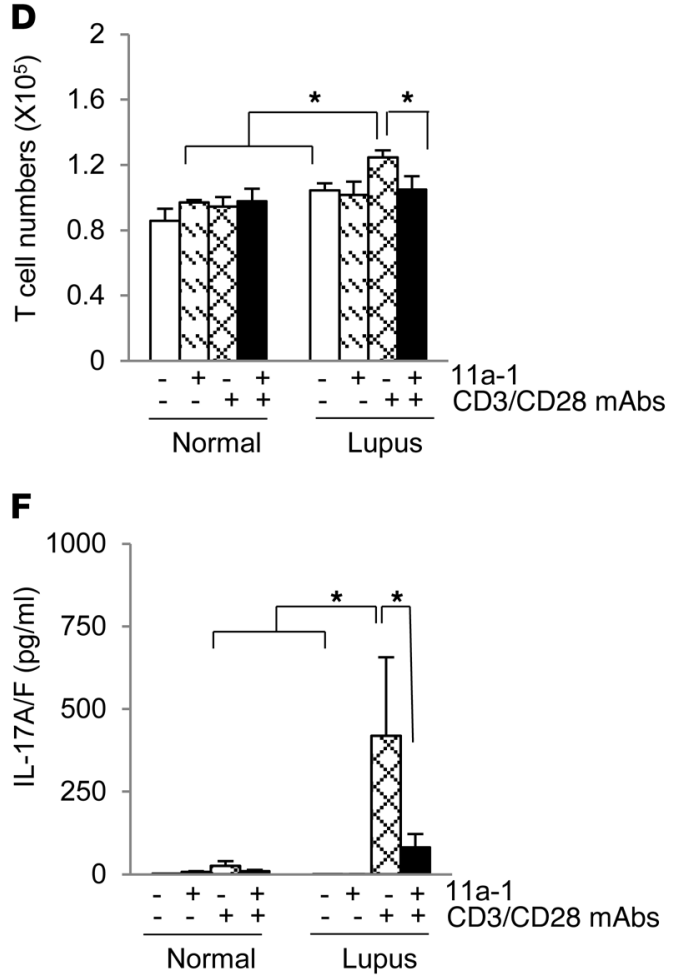

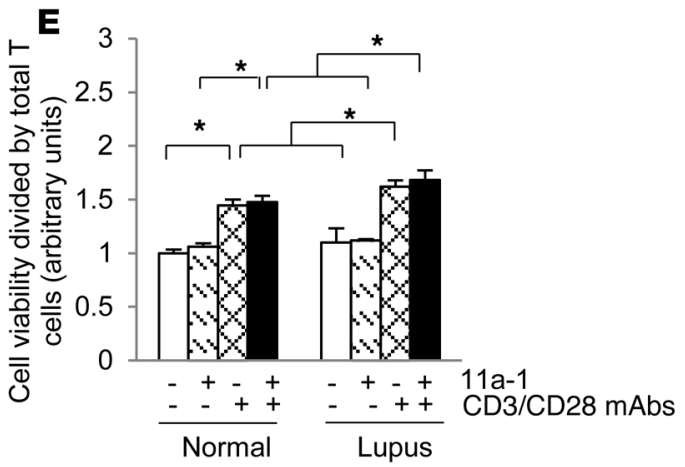

G

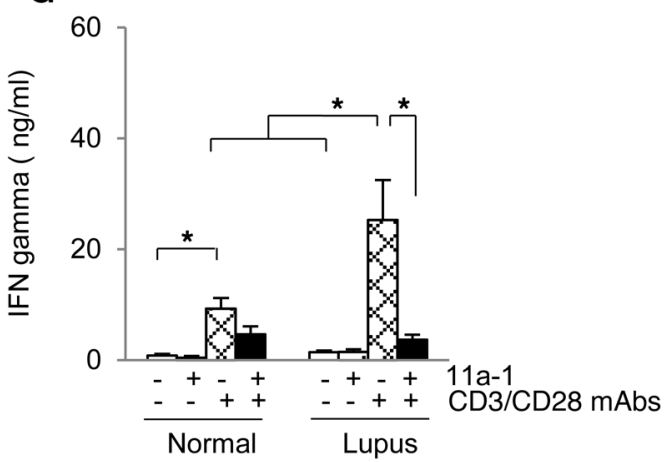

Figure 8. SHP2 also modulates proliferation of $T$ cells and expression of IFN- $\gamma$ and IL-17A/F in human lupus. Serum levels of (A) IL-17A/F and (B) IFN- $\gamma$ were measured from either normal or lupus patients with SLEDAI scores higher than 7. $n$ = 24-25/group. (C) Representative images of cultured normal or lupus patient T cells, isolated from PBMCs, following 48 hours of culture in the presence of vehicle (DMSO) or 11a-1 (10 $\mu \mathrm{g} /$ $\mathrm{ml}$ ) and in the absence or presence of activating antibodies anti-CD3 and anti-CD28. Scale bar: $500 \mu \mathrm{m}$. T cells isolated from normal or lupus patients were assessed for (D) proliferation and (E) viability $(n=3$ independent experiments) after 48 hours of culture. In addition, $T$ cells isolated from normal or lups patients were measured for levels of (F) IL-17A/F or (C) IFN- $\gamma$ following 120 hours of culture. $n$ $=12-13 /$ group. ${ }^{*} P<0.05,1-$ way or 2-way ANOVA with HolmSidak post-test when ANOVA was significant. indicate that SHP2 inhibition can similarly improve proteinuria and kidney function, we believe it is through a different mechanism; here, we show a decrease in proliferation of $\mathrm{T}$ cells, not $\mathrm{B}$ cells, an increase in ERK/MAPK activity, and a decrease in production of IFN- $\gamma$ and IL-17A/F cytokines in MRL/lpr mice. More- over, SHP2 activity does not significantly affect serological neutrophil, monocyte, or eosinophil populations and does not reduce elevated circulating levels of IL-6, TNF- $\alpha$, or IL-17A/A cytokines, suggesting functional specificity of SHP2 for ERK/MAPK, not $\mathrm{PI} 3 \mathrm{~K} / \mathrm{AKT} / \mathrm{mTOR}$, signaling in SLE. 
IFN- $\gamma$ is required for lupus development, inducing local immune and inflammatory signaling processes (78). Moreover, while the role for IL-17A/A has been well studied, the function of the heterodimer IL-17A/F in SLE remains elusive, though its expression has been documented in inflammation (79). Here, the differential effect of SHP2 inhibition on IL-17A/F but not IL-17A/A homodimer is interesting, particularly since IL-17A/F heterodimers signal through the same receptors as IL-17A or IL-17F homodimers and induce similar biological responses. Interestingly, recent work in RA has identified specific regulation of the different isoforms of IL-17 in human pathogenesis. While the plasma levels of IL-17A, IL-17A/F, and IL-17F were all significantly increased in RA, the differences were largest in IL-17F, and only this isoform was decreased following methotrexate therapy (80). Taken together, these data suggest that regulation of autoimmune diseases may not only be dependent on a specific subset of cytokines, but also on the expression of specific isoforms of these cytokines as well. We are currently investigating the potential contribution of cytokines and their isoforms downstream of SHP2 in our laboratory.

Besides affecting cell proliferation, SHP2 is also involved in cell migration. As such, inhibition of SHP2 may prevent activated $\mathrm{T}$ cells from migrating to target organs. This was recently suggested in the study utilizing the NSC-87877 SHP2 inhibitor, where the preventative effects of the drug in EAE were mediated through its ability to block migration of $\mathrm{T}$ cells into the central nervous system (65). Therefore, 11a-1 treatment may function similarly, at least in part, and prevent the migration of $\mathrm{T}$ cells and inflammatory cells into SLE-targeted organs such as the spleen and kidney.

Regrettably, inhibition of SHP2 does not cure SLE; it did not decrease production of anti-dsDNA or anti-IgG, despite the profound observed amelioration in overall pathogenicity of the disease in tissues. Indeed, our data suggest that targeting of downstream autoreactive $\mathrm{T}$ cells alone may be sufficient to suppress SLE-associated organ damage. However, we cannot exclude the possibility that subpopulations of B cells are also required, at least in part, for this process. Provocatively, these data also suggest that autoantibody production may be necessary, but insufficient, in mediating the organ damage in SLE, data well in line with accumulating evidence that suggests the same. For example, treatment of MRL/lpr mice with IL-2 significantly improved lupus pathogenicity without altering serum autoantibody levels or immunocomplex deposits in the kidney (5). Moreover, although there was a significant decrease in autoantibody isotypes in ICOS-deficient $\mathrm{MRL} / \mathrm{lpr}$ mice, the renal pathology, as demonstrated by the degree of glomerulonephritis and interstitial inflammation, was comparable (81), demonstrating that autoantibody production and tissue inflammation may not be concomitantly correlated.

There is no question that new drug development for the treatment of lupus is needed. The current therapeutic regimen is limited, and SLE is a complicated, multifaceted disease that may require targeting of multiple downstream effectors. Perhaps combinatorial therapies that include B and T cell inhibitors or SHP2 and PI3K/ AKT inhibitors would help elicit a more positive response. Additional options may include other downstream targets. For instance, animal studies that inhibit cytokine production of IFN- $\gamma$ show some improvement in lupus (82). In addition, reverse epigenetic modifications by the histone deacetylase (HDAC) inhibitor trichostatin
A or suberoylanilide hydroxamic acid also improve lupus pathogenicity (83). Here, inhibition of SHP2 activity blocks DN T cell proliferation, leading to decreased IFN- $\gamma$ and IL-17AF levels and to increased ERK activity, ultimately normalizing SLE-associated pathogenicity in target tissues. As such, these data suggest SHP2 activity is integrally involved in SLE and that its normalization may be a potent and targeted therapy for treatment of patients with SLE.

\section{Methods}

Mice. Mice utilized herein were maintained in a specific pathogenfree (SPF) animal facility at BIDMC. Briefly, female MRL/MpJ-fas $l p r$ (MRL/lpr), MRL/MpJ, and C57BL/6J mice were purchased from the Jackson Laboratory. For experimental controls, we utilized female C57BL/6 WT mice as well as the lupus background strain (MRL/ MpJ) mice, which do not have the recessive lpr gene mutation that the $\mathrm{MRL} / \mathrm{lpr}$ mice have, but that still develop a late-onset, mild arthritis and glomerulonephritis (38). For experiments, mice within each group were subjected to i.p. injections of either vehicle (DMSO) or 11a-1, a potent, reversible, and specific SHP2 inhibitor (39), at a dosage of $7.5 \mathrm{mg} / \mathrm{kg} / \mathrm{d}$ for a period of 6 weeks, starting at 12 weeks to 18 weeks of age. Body weight was measured daily, and treatment concentrations and volumes were adjusted accordingly. At the end of the treatment period, mice were sacrificed with $\mathrm{CO}_{2}$ exsanguination and SLE-targeted organs were removed. For each mouse, spleen and kidney weight were calculated. In addition, total animal body weight and tibia length were measured. Peripheral blood/serum was also collected for cell counts and cytokine assays, described below.

Human PBMC isolation. Deidentified human PBMCs were isolated from both normal and SLE patients, and SLE patients were diagnosed according to the American College of Rheumatology classification criteria and with an SLE Disease Activity Index (SLEDAI) greater than or equal to 7. Healthy sex- and age-matched control cells were also used for experiments herein. Briefly, peripheral venous blood was collected in heparin-lithium tubes and PBMCs were prepared with Ficoll-Paque centrifugation, as previously described (84).

Immune complex PTP assays. PTP assays were conducted as previously described (85) using para-nitrophenyl phosphate (pNPP) (Sigma-Aldrich) as substrate. Briefly, WT C57BL/6, MRL/MpJ, or $\mathrm{MRL} / \mathrm{lpr}$ mouse spleens were homogenized and lysed in RIPA buffer (but without sodium orthovanadate), and SHP2, SHP1, and PTPN22 were immunoprecipitated by using anti-SHP2, anti-SHP1, and antiPTPN22 antibodies (Santa Cruz Biotechnology Inc.) coupled to protein A-Sepharose. The SHP2, SHP1, and PTPN22 immune complexes were washed 6 times in RIPA buffer without sodium orthovanadate and once in assay buffer (30 mM HEPES, pH 7.4, $120 \mathrm{mM} \mathrm{NaCl}$ without pNPP). For each sample, PTP assays were performed in triplicate at $37^{\circ} \mathrm{C}$ in $50 \mu \mathrm{l}$ of assay buffer (30 mM HEPES, pH 7.4, $120 \mathrm{mM} \mathrm{NaCl}, 5$ $\mathrm{mM}$ dithiothreitol, $10 \mathrm{mM}$ pNPP) containing $50 \mu$ l of the SHP2 beads. Reactions were terminated with $0.2 \mathrm{~N} \mathrm{NaOH}$, and phosphate release was determined by measuring A410. Following the assays, immune complexes were recovered by centrifugation, boiled in $2 \times$ SDS-PAGE sample buffer, resolved by SDS-PAGE, and immunoblotted with antiSHP2, anti-SHP1, and anti-PTPN22 antibodies, respectively (Santa Cruz Biotechnology Inc.) to ensure that equal amounts of SHP2, SHP1, and PTPN22 had been tested for phosphatase activity.

Assay for reversibility of the SHP2 inhibitor. SHP2 immunocomplexes were washed $6 \times$ in RIPA buffer and then, in the presence of 
$500 \mu \mathrm{l}$ RIPA buffer, were either treated with $11 \mathrm{a}-1(10 \mu \mathrm{g} / \mathrm{ml})$ or vehicle (DMSO). Complexes were incubated for 5 hours at $4^{\circ} \mathrm{C}$ and then washed in RIPA buffer for the indicated times $(0 \times, 5 \times, 15 \times$, or $30 \times)$. A last wash in assay buffer without DTT and pNPP was conducted before performing the PTP assay (as described in Immune complex PTP assays). For the reaction controls, following the 11a-1 or DMSO incubation, SHP2 immunocomplexes were immediately washed with assay buffer without DTT and PNPP and then subjected to the PTP assay.

Biochemical analyses. Spleens isolated from either vehicle (DMSO) or 11a-1-treated WT C57BL/6, MRL/MpJ, or MRL/lpr female mice were dissected, perfused in PBS, and immediately frozen in liquid $\mathrm{N}_{2}$. Whole-tissue lysates were prepared by homogenizing the tissue in RIPA buffer $(25 \mathrm{mmol} / \mathrm{l}$ Tris-HCl, $\mathrm{pH} 7.4,150 \mathrm{mmol} / \mathrm{l} \mathrm{NaCl}, 0.1 \%$ SDS, $1 \%$ NP-40, 0.5\% sodium deoxycholate, $5 \mathrm{mmol} / 1 \mathrm{EDTA}, 1 \mathrm{mmol} / \mathrm{l} \mathrm{NaF}$, $1 \mathrm{mmol} / 1$ sodium orthovanadate, and a protease cocktail) at $4^{\circ} \mathrm{C}$, followed by clarification at $14,000 \mathrm{~g}$. Proteins were resolved by SDS-PAGE and transferred to PVDF membranes. Immunoblots were performed on whole lysates, following the manufacturer's directions, with antiAKT (sc-8312), anti-SHP2 (sc-280), anti-phospho-AKT (4060S), antiphospho-ERK1/2 (9101L), anti-ERK1/2 (9102L), anti-phospho-p70S6K (9234S), anti-p70S6K (9292L), anti-phospho-S6RP (2211S), and antiS6RP (2217S) antibodies (Cell Signaling Technology); and anti-GAPDH (MAB374) (Millipore). Bands were visualized with enhanced chemiluminescence and quantified by densitometry (ImageJ; NIH).

Urinalysis. To determine kidney function, urine was collected before mice were sacrificed. Albumin and creatinine in the urine were measured using colorimetric assays according to the manufacturer's instructions (Albuwell M; the creatinine companion, Exocell) by ELISA, as described below. Kidney function was calculated as ratio of albumin to creatinine levels.

Histology. Harvested organs for histology were flushed with PBS, perfusion fixed in Bouin's reagent, and paraffin embedded. Sections $(5 \mu \mathrm{m})$ were stained with H\&E, periodic acid-Schiff stain (PAS), or Masson's trichrome at the Harvard Medical School Rodent Histopathology Core and scored using an unbiased and blinded approach by Roderick Bronson. Scores were based on a scale of 0-4, as follows: 4 , most severe, based on appearance of crushed glomeruli and thickness of crescents; 3 , severe; 2 , moderate; 1 , mild; 0 , appearing normal. We took an average severity based upon evaluation of multiple glomeruli per kidney. Images of the tissue sections were obtained using a Keyence BZ-9000 microscope.

Longevity study. Female MRL/lpr mice survival/longevity was assessed by Kaplan-Meier curve analysis. Mice were either i.p. injected with vehicle (DMSO) or 11a-1 $(7.5 \mathrm{mg} / \mathrm{kg} / \mathrm{d})$ beginning at 12 weeks of age to assess tolerance of the inhibitor and longevity/ survival. The study was terminated when the last vehicle-treated MRL/lpr mouse died, at 26 weeks.

Blood cell counts. $50 \mu \mathrm{l}$ of peripheral blood was collected from mice upon sacrifice and mixed with $5 \mathrm{mM}$ EDTA anticoagulant to be used for blood cell counts (Hemavet 850FS), to determine numbers of wbc (neutrophil, lymphocytes, monocytes, eosinophil, and basophil), rbc, and platelets. In addition, peripheral blood isolated from MRL/lpr mice either treated with vehicle (DMSO) or 11a-1 was used to count the percentage of leukocyte subsets, including B cells, $\mathrm{T}$ cells, and $\mathrm{T}$ cell subsets ( $\mathrm{CD}^{+}, \mathrm{CD}^{+}$, and DN T cells), by flow cytometry (see below).

Total cell isolation from SLE-prone tissues (kidney, spleen). Singlecell suspensions from excised kidneys and spleens from either vehicle or 11a-1-treated mice were obtained by passing the organs through a nylon mesh. Briefly, kidneys were cut into small pieces and homogenized on a $70-\mu \mathrm{m}$ nylon mesh in $5 \mathrm{ml}$ of HBSS buffer. All of the homogenized tissues and cells were transferred to new 50-ml tubes and digested with collagenase type $4(100 \mu \mathrm{g} / \mathrm{ml})$ (Worthington Biochemical Corp.) in HBSS for 30 minutes to 2 hours $\left(37^{\circ} \mathrm{C}\right)$ on a rotating shaker. After digestion, the cells were centrifuged at $780 \mathrm{~g}$ for 10 minutes, and the kidney cell isolates were generated; these included infiltrated immune cell subsets.

Spleens were cut into 2 to 3 pieces each and homogenized on a $70-\mu \mathrm{m}$ nylon mesh in $5 \mathrm{ml}$ of HBSS buffer. The cells were filtered through a $70-\mu \mathrm{m}$ nylon mesh to a new $50-\mathrm{ml}$ tube and centrifuged at $780 \mathrm{~g}$ for 5 minutes at room temperature. The pellets were dissolved in 1 to $2 \mathrm{ml}$ of rbc lysis buffer (Sigma-Aldrich R7757) for 2 to 5 minutes to lyse the rbc. $30 \mathrm{ml}$ of $1 \times$ HBSS buffer was added, and the homogenate was centrifuged at $780 \mathrm{~g}$ for 10 minutes. The pellet, containing immune cell subsets and remaining tissue aggregates, was further dissolved in $5 \mathrm{ml}$ of HBSS and additionally filtered through a new $70-\mu \mathrm{m}$ nylon mesh to remove these aggregates. Finally the remaining cell suspension was centrifuged at $780 \mathrm{~g}$ at $4^{\circ} \mathrm{C}$ for 5 minutes to collect the splenocytes, which included the immune cell subsets.

All the isolated cell pellets were dissolved in $1 \mathrm{ml}$ of $0.5 \% \mathrm{FBS} /$ PBS buffer in preparation for either cell counting or flow cytometry, as described below.

Flow cytometry. To identify immune cell subsets, isolated cells from tissues or whole blood were immunostained with mouse antibodies targeted against CD3e (145-2C11, BioLegend), CD4 (GK1.5, BioLegend), CD8 (53-6.7, eBioscience), CD45 (30-F11, eBioscience), CD19 (6125, BioLegend), CD11b (M1170, BioLegend), TCR $\beta$ (H57-597, BioLegend), CD44 (IM7, BioLegend), B220 (RA3-6B2, BD Biosciences - Pharmingen), CD138 (281-2, BioLegend), CD38 (CD28.2, BioLegend), Ly6G (RB6.8C5, eBioscience), PSGL-1 (2PH1, BD), CD62L (DREG-56, BioLegend), or CD25 (PC61, BioLegend) for 30 minutes at $4^{\circ} \mathrm{C}$. Samples were acquired on a LSR II flow cytometer (BD Biosciences), and the percentage of each subpopulation of cells (B cells, T cells, monocytes, macrophages, and neutrophils) was assessed by FlowJo (version 7.2.2, Tree Star). Total cell numbers were counted using a hemocytometer. Absolute cell numbers for each subpopulation were calculated based on the percentage of each population.

Purification and culture of mouse and human T cells. Whole tissue cell cultures prepared from mouse spleen and axillary lymph nodes were generated as described above. From within this total cell preparation, total $\mathrm{T}$ cells from spleen and the DN T cells from axillary lymph nodes were further purified through negative selection using a pan $\mathrm{T}$ cell isolation kit from Miltenyi Biotec. In brief, $10 \mu \mathrm{l}$ of pan T cell biotin-antibody cocktail, which includes monoclonal antibodies against CD11b, Cd11c, CD19, CD45R (B220), CD49b, CD105, anti-MHC class II, and ter-19, was added per $1 \times 10^{7}$ total cells, incubated on ice for 30 minutes, and then mixed with $30 \mu \mathrm{l}$ of D-PBS/0.5\% FBS ( $\mathrm{pH} 7.2)$ per $1 \times 10^{7}$ cells. Next, $20 \mu$ of anti-biotin beads were added per $1 \times 10^{7}$ cells and the reaction was kept on ice for another 30 minutes. After centrifuging at $200 \mathrm{~g}$ for 5 minutes at $4^{\circ} \mathrm{C}$, the pellet was resuspended in $2 \mathrm{ml}$ of $\mathrm{T}$ cell isolation buffer (D-PBS, pH 7.2, 0.5\% FBS, and 2 mM EDTA) and the T cells were purified through a magnetic sorting column (MACS).

Human T cells were purified from frozen PBMCs isolated from SLE or normal donor patients. Briefly, frozen PBMCs were thawed in a $37^{\circ} \mathrm{C}$ water bath for 1 to 2 minutes and then gently added to prewarmed RPMI 
1640 medium with $10 \%$ FBS (total $10 \mathrm{ml}$ ). After incubating at $37^{\circ} \mathrm{C}$ for 1 hour, the cells were centrifuged at $250 \mathrm{~g}$ for 5 minutes at room temperature. The cell pellet was washed with $5 \mathrm{ml}$ of prewarmed RPMI 1640 medium with 10\% FBS 3 times, followed by a final D-PBS (no calcium, no magnesium buffer) wash. Human T cells were then purified by a Pan T Cell Isolation Kit (human) from Miltenyi Biotec, as described above.

The purity of isolated $\mathrm{T}$ cells routinely exceeded $94 \%$. After purification, T cells were resuspended in RPMI 1640 medium with $10 \%$ FBS, and $1 \times 10^{5}$ cells/well in $100 \mu \mathrm{l}$ total volume was loaded onto a 96-well plate, either left uncoated or precoated with anti-CD3 antibody $(1 \mu \mathrm{g} / \mathrm{ml})$ (OKT3; BioLegend). All cells loaded onto wells precoated with anti-CD3 antibody were also mixed with anti-CD28 antibody $(0.5 \mu \mathrm{g} / \mathrm{ml})(\mathrm{CD} 28.2$; BioLegend) to help potentiate the $\mathrm{T}$ cell signaling response. Plated cells were then cultured for 48 or 120 hours in the presence of either vehicle (DMSO) or 11a-1 $(10 \mu \mathrm{g} / \mathrm{ml})$. Following incubation, $15 \mu$ of medium was collected for the various cytokine activity analyses, as described above.

$T$ cell proliferation and viability assays. For cell viability, an MTT (Thiazolyl Blue Tetrazolium Bromide, M2128, Sigma-Aldrich) assay was employed. Briefly, $10 \mu \mathrm{l}$ of the MTT-labeling reagent (final concentration $0.5 \mathrm{mg} / \mathrm{ml}$ ) was loaded into each cell culture well (96-well plate) and then incubated for 4 hours in a humidified chamber. Following incubation, $100 \mu \mathrm{l}$ of solubilization solution $(0.04 \mathrm{~N}$ in absolute isopropanol) was added to each well, resuspended, and then incubated at $37^{\circ} \mathrm{C}$ for an additional hour. Spectrophotometric absorbance of the samples was assessed using a microplate reader at a wavelength of $595 \mathrm{~nm}$. T cell numbers and proliferation were assessed by cell count using a hemocytometer. In brief, $1 \times 10^{5}$ cells were plated in each well and cultured for 48 hours. $10 \mu$ of cell suspension was then removed and mixed together with $10 \mu$ of Trypan blue solution (0.4\%, T8154, Sigma-Aldrich). After mixing, $10 \mu$ of the mixture was loaded onto the hemocytometer and the total average number of cells/well was calculated.

ELISA. ELISA assays were used to detect for the presence of various cytokines in mouse serum isolated from vehicle or drug-treated animals or from medium supernatant isolated from tissue cell cultures as described above. ELISA was also used to detect total IgG and dsDNA IgG from mouse serum and for detection of albumin and creatinine from urine. ELISA detection kits for mouse cytokines IL-6 and TNF- $\alpha$ were purchased from eBioscience, mouse cytokines IL-17A, IL$17 \mathrm{~A} / \mathrm{F}, \mathrm{IFN}-\gamma$, and human IFN- $\gamma$ were purchased from BioLegend, kits for the albumin and creatinine were purchased from Exocell, and kits for the serum IgG and anti-dsDNA IgG were purchased from Alpha Diagnostic International Inc. ELISAs were all performed according to the manufacturer's instructions.

Cytokine analyses. In brief, capture antibodies for each cytokine were precoated on 96 -well plates overnight at $4^{\circ} \mathrm{C}$, then $100 \mu \mathrm{l}$ of $5 \times$ diluted serum or $300 \times$ diluted supernatant medium was loaded on the precoated wells in duplicate and left overnight at $4^{\circ} \mathrm{C}$ (with the exception of the human IFN- $\gamma$ assay isolated from supernatant medium, where the dilution used was 1:30). As per the protocol instructions, enzyme-antibody conjugate, TMB substrate, and stopping buffer were added sequentially. The colorimetric analysis, as measured by OD within each well, was determined using a microplate reader set at a wavelength of $450 \mathrm{~nm}$. The cytokine concentrations were calculated and measured against a standard curve for each cytokine.

Serum IgG and anti-dsDNA IgG. $100 \mu$ lof 1:50000× diluted serum for IgG and $100 \mu \mathrm{l}$ of 1:20000× diluted serum for dsDNA IgG were used and loaded onto a precoated 96-well plate in duplicate for 1 hour at room temperature. As per the protocol instructions, enzymeantibody conjugate, TMB substrate, and stopping buffer were added sequentially. The OD of the wells was determined using a microplate reader set at a wavelength of $450 \mathrm{~nm}$.

Albumin and creatinine levels. For the albumin assay, collected mouse urine was diluted at 1:5200x and $50 \mu \mathrm{l}$ was loaded onto an precoated albumin 96-well plate, followed by primary incubation, secondary incubation, and colorimetric determination. For the creatinine assay, the urine was diluted $20 \times$ and loaded onto a 96-well plate, and picrate working solution and acid reagent were added sequentially according to protocol. Absorbance was assayed using a plate reader set at a wavelength of $495 \mathrm{~nm}$.

Statistics. All data are expressed as mean \pm SEM. Statistical significance was determined using 2-tailed Student's $t$ test and 1-way ANOVA or 2-way repeated-measures ANOVA, as appropriate. If ANOVA was significant, individual differences were evaluated using the Holm-Sidak post-test. For all studies, values of $P<0.05$ were considered statistically significant.

Study approval. All procedures were performed in accordance with the NIH Guide for the Care and Use of Laboratory Animals (National Academies Press. 2011.) and experimental protocols were approved by the IACUC at BIDMC (protocol number 070-2014). In addition, deidentified human PBMCs were obtained for this study from the Division of Rheumatology at BIDMC in accordance and with approval by the IRB at BIDMC. SLE patients were recruited by the Division of Rheumatology at BIDMC under IRB protocol 2006-P-0298.

\section{Author contributions}

JW performed the majority of the experiments, analyzed the data, and edited the manuscript. MM conducted the flow cytometry analysis on the immune subtypes isolated from the mouse tissues. LFZ generated the SHP2 inhibitor compound (11a-1) for these studies. RB conducted the histology and score analyses. MF collected the blood samples from human patients. VCK provided us with deidentified serum, PBMCs, and T cells from SLE patients. CT, GCT, and ZYZ advised on parts of the study, helped analyze data, and edited the paper. MIK directed the study, analyzed and approved all of the data, and wrote and edited the paper.

\section{Acknowledgments}

This work is dedicated to Ekaterini Kontaridis, whose inspiration and grace motivated this work on lupus. This work was supported by NIH grants R01-HL102368 and R01-HL114775 and the Alliance for Lupus Research Foundation (to M.I. Kontaridis); R01-CA152194 and R01-CA69202 (to Z.Y. Zhang); and R01-NIAID42269A1 (to G.C. Tsokos); and R01-AR060849 (to V.C. Kyttaris). This work was also supported in part by funding from GSK and the BIDMC Division of Cardiology (to M.I. Kontaridis). SHP2 inhibitor (11a-1) can be obtained from Z.Y. Zhang at zyzhang@iupui.edu.

Address correspondence to: Maria Irene Kontaridis, Beth Israel Deaconess Medical Center, Department of Medicine, Division of Cardiology, Center for Life Sciences, Room 908, 3 Blackfan Circle, Boston, Massachusetts 02115, USA. Phone: 617.735.4248; E-mail: mkontari@bidmc.harvard.edu. 
1. Tsokos GC. Systemic lupus erythematosus. N Engl JMed. 2011;365(22):2110-2121.

2. Frostegard J. SLE, atherosclerosis and cardiovascular disease. J Intern Med. 2005;257(6):485-495.

3. Kaplan MJ. Neutrophils in the pathogenesis and manifestations of SLE. Nat Rev Rheumatol. 2011;7(12):691-699.

4. Konya C, Paz Z, Tsokos GC. The role of T cells in systemic lupus erythematosus: an update. Curr Opin Rheumatol. 2014;26(5):493-501.

5. Mizui M, et al. IL-2 protects lupus-prone mice from multiple end-organ damage by limiting CD4-CD8- IL-17-producing T cells. J Immunol. 2014;193(5):2168-2177.

6. Foster MH. T cells and B cells in lupus nephritis. Semin Nephrol. 2007;27(1):47-58.

7. Koga T, Ichinose K, Mizui M, Crispin JC, Tsokos GC. Calcium/calmodulin-dependent protein kinase IV suppresses IL-2 production and regulatory $\mathrm{T}$ cell activity in lupus. J Immunol. 2012;189(7):3490-3496.

8. Crispin JC, et al. Cutting edge: protein phosphatase $2 \mathrm{~A}$ confers susceptibility to autoimmune disease through an IL-17-dependent mechanism. J Immunol. 2012;188(8):3567-3571.

9. Douroudis K, et al. Protein tyrosine phosphatase non-receptor type 22 gene variants at position 1858 are associated with type 1 and type 2 diabetes in Estonian population. Tissue Antigens. 2008;72(5):425-430.

10. Kariuki SN, Niewold TB. Genetic regulation of serum cytokines in systemic lupus erythematosus. Transl Res. 2010;155(3):109-117.

11. Kariuki SN, Crow MK, Niewold TB. The PTPN22 C1858T polymorphism is associated with skewing of cytokine profiles toward high interferon- $\alpha$ activity and low tumor necrosis factor alpha levels in patients with lupus. Arthritis Rheum. 2008;58(9):2818-2823.

12. Karlson EW, Costenbader KH. Epidemiology: Interpreting studies of interactions between RA risk factors. Nat Rev Rheumatol. 2010;6(2):72-73.

13. Vogel A, Strassburg CP, Manns MP. 77 C/G mutation in the tyrosine phosphatase $\mathrm{CD} 45$ gene and autoimmune hepatitis: evidence for a genetic link. Genes Immun. 2003;4(1):79-81.

14. Nath SK, Quintero-Del-Rio AI, Kilpatrick J, Feo L, Ballesteros M, Harley JB. Linkage at 12q24 with systemic lupus erythematosus (SLE) is established and confirmed in Hispanic and European American families. Am J Hum Genet. 2004;74(1):73-82.

15. Van Vactor D, O'Reilly AM, Neel BG. Genetic analysis of protein tyrosine phosphatases. Curr Opin Genet Dev. 1998;8(1):112-126.

16. Feng G. SHP-2 tyrosine phosphatase: signaling one cell or many. Exp Cell Res. 1999;253(1):47-54.

17. Tonks NK, Neel BG. Combinatorial control of the specificity of protein tyrosine phosphatases. Curr Opin Cell Biol. 2001;13(2):182-195.

18. Hof P, Pluskey S, Dhe-Pagganon S, Eck MJ, Shoelson SE. Crystal structure of the tyrosine phosphatase SHP-2. Cell. 1998;92(4):441-450.

19. Barford D, Neel BG. Revealing mechanisms for $\mathrm{SH} 2$ domain mediated regulation of the protein tyrosine phosphatase SHP-2. Structure. 1998;6(3):249-254.
20. O'Reilly AM, Neel BG. Structural Determinants of SHP-2 Function and Specificity in Xenopus Mesoderm Induction. Mol Cell Biol. 1998;18(1):161-177.

21. Burch M, Sharland M, Shinebourne E, Smith G, Patton M, McKenna W. Cardiologic abnormalities in Noonan syndrome: phenotypic diagnosis and echocardiographic assessment of 118 patients. J Am Coll Cardiol. 1993;22(4):1189-1192.

22. Marino B, Digilio MC, Toscano A, Giannotti A, Dallapiccola B. Congenital heart diseases in children with Noonan syndrome: An expanded cardiac spectrum with high prevalence of atrioventricular canal. J Pediatr. 1999;135(6):703-706.

23. Keilhack H, David FS, McGregor M, Cantley LC, Neel BG. Diverse biochemical properties of Shp2 mutants. J Biol Chem. 2005;280(35):30984-30993.

24. O'Reilly AM, Pluskey S, Shoelson SE, Neel BG. Activated mutants of SHP-2 preferentially induce elongation of Xenopus animal caps. Mol Cell Biol. 2000;20(1):299-311.

25. Fragale A, Tartaglia M, Wu J, Gelb BD. Noonan syndrome-associated SHP2/PTPN11 mutants cause EGF-dependent prolonged GAB1 binding and sustained ERK2/MAPK1 activation. Hum Mutat. 2004;23(3):267-277.

26. Araki T, et al. Mouse model of Noonan syndrome reveals cell type- and gene dosagedependent effects of Ptpn11 mutation. Nat Med. 2004;10(8):849-857.

27. Niihori T, et al. Functional analysis of PTPN11/ SHP-2 mutants identified in Noonan syndrome and childhood leukemia. J Hum Genet. 2005;50(4):192-202.

28. Tartaglia M, et al. Diversity and functional consequences of germline and somatic PTPN11 mutations in human disease. Am J Hum Genet. 2006;78(2):279-290.

29. Schubbert S, et al. Functional analysis of leukemia-associated PTPN11 mutations in primary hematopoietic cells. Blood. 2005;106(1):311-317.

30. Martin DM, Gencyuz CF, Petty EM. Systemic lupus erythematosus in a man with Noonan syndrome. Am J Med Genet. 2001;102(1):59-62.

31. Lisbona MP, Moreno M, Orellana C, Gratacos J, Larrosa M. Noonan syndrome associated with systemic lupus erythematosus. Lupus. 2009;18(3):267-269.

32. Leventopoulos G, Denayer E, Makrythanasis P, Papapolychroniou C, Fryssira H. Noonan syndrome and systemic lupus erythematosus in a patient with a novel KRAS mutation. Clin Exp Rheumatol. 2010;28(4):556-557.

33. Lopez-Rangel E, Malleson PN, Lirenman DS, Roa $\mathrm{B}$, Wiszniewska J, Lewis ME. Systemic lupus erythematosus and other autoimmune disorders in children with Noonan syndrome. Am JMed Genet A. 2005;139(3):239-242.

34. Alanay Y, Balci S, Ozen S. Noonan syndrome and systemic lupus erythematosus: presentation in childhood. Clin Dysmorphol. 2004;13(3):161-163.

35. Amoroso A, et al. The unusual association of three autoimmune diseases in a patient with Noonan syndrome. J Adolesc Health. 2003;32(1):94-97.

36. Singer GG, Carrera AC, Marshak-Rothstein A, Martinez C, Abbas AK. Apoptosis, Fas and systemic autoimmunity: the MRL-lpr/lpr model.
Curr Opin Immunol. 1994;6(6):913-920.

37. Wakeland EK, Wandstrat AE, Liu K, Morel L. Genetic dissection of systemic lupus erythematosus. Curr Opin Immunol. 1999;11(6):701-707.

38. Warner LM, Adams LM, Sehgal SN. Rapamycin prolongs survival and arrests pathophysiologic changes in murine systemic lupus erythematosus. Arthritis Rheum. 1994;37(2):289-297.

39. Zeng LF, et al. Therapeutic Potential of Targeting the Oncogenic SHP2 Phosphatase. J Med Chem. 2014;57(15):6594-609.

40. Wu CJ, O'Rourke DM, Feng GS, Johnson GR, Wang $\mathrm{Q}$, Greene MI. The tyrosine phosphatase SHP-2 is required for mediating phosphatidylinositol 3-kinase/Akt activation by growth factors. Oncogene. 2001;20(42):6018-6025.

41. Barber DF, et al. PI3Kgamma inhibition blocks glomerulonephritis and extends lifespan in a mouse model of systemic lupus. Nat Med. 2005;11(9):933-935.

42. Neel BG, Gu H, Pao L. The 'Shp'ing news: SH2 domain-containing tyrosine phosphatases in cell signaling. Trends Biochem Sci. 2003;28(6):284-293.

43. Deng $C$, et al. Decreased Ras-mitogen-activated protein kinase signaling may cause DNA hypomethylation in $\mathrm{T}$ lymphocytes from lupus patients. Arthritis Rheum. 2001;44(2):397-407.

44. Sawalha AH, et al. Defective T-cell ERK signaling induces interferon-regulated gene expression and overexpression of methylation-sensitive genes similar to lupus patients. Genes Immun. 2008;9(4):368-378.

45. Gorelik G, Richardson B. Key role of ERK pathway signaling in lupus. Autoimmunity. 2010;43(1):17-22.

46. Sunahori K, Nagpal K, Hedrich CM, Mizui M, Fitzgerald LM, Tsokos GC. The catalytic subunit of protein phosphatase $2 \mathrm{~A}$ (PP2Ac) promotes DNA hypomethylation by suppressing the phosphorylated mitogen-activated protein kinase/ extracellular signal-regulated kinase (ERK) kinase (MEK)/phosphorylated ERK/DNMT1 protein pathway in T-cells from controls and systemic lupus erythematosus patients. J Biol Chem. 2013;288(30):21936-21944.

47. Dai C, Liu Z, Zhou H, Li L. Monocyte chemoattractant protein-1 expression in renal tissue is associated with monocyte recruitment and tubulo-interstitial lesions in patients with lupus nephritis. Chin Med J (Engl). 2001;114(8):864-868.

48. Crispin JC, Tsokos GC. Human TCR- $\alpha \beta^{+}$CD 4 CD8 ${ }^{-} \mathrm{T}$ cells can derive from $\mathrm{CD} 8^{+} \mathrm{T}$ cells and display an inflammatory effector phenotype. JImmunol. 2009;183(7):4675-4681.

49. Rodriguez-Rodriguez N, et al. Programmed cell death 1 and Helios distinguish TCR- $\alpha \beta^{+}$ double-negative ( $\left.\mathrm{CD}^{-} \mathrm{CD} 8^{-}\right) \mathrm{T}$ cells that derive from self-reactive CD8 T cells. JImmunol. 2015;194(9):4207-4214.

50. Dean GS, Anand A, Blofeld A, Isenberg DA, Lydyard PM. Characterization of $\mathrm{CD} 3^{+} \mathrm{CD} 4{ }^{-} \mathrm{CD} 8$ (double negative) $\mathrm{T}$ cells in patients with systemic lupus erythematosus: production of IL-4. Lupus. 2002;11(8):501-507.

51. Baechler EC, Gregersen PK, Behrens TW. The emerging role of interferon in human systemic lupus erythematosus. Curr Opin Immunol. 
2004;16(6):801-807.

52. Blanco P, Palucka AK, Gill M, Pascual V, Banchereau J. Induction of dendritic cell differentiation by IFN- $\alpha$ in systemic lupus erythematosus. Science. 2001;294(5546):1540-1543.

53. Cross JT, Benton HP. The roles of interleukin-6 and interleukin-10 in B cell hyperactivity in systemic lupus erythematosus. Inflamm Res. 1999;48(5):255-261.

54. Csiszar A, Nagy G, Gergely P, Pozsonyi T, Pocsik E. Increased interferon-gamma (IFN- $\gamma$ ), IL-10 and decreased IL-4 mRNA expression in peripheral blood mononuclear cells (PBMC) from patients with systemic lupus erythematosus (SLE). Clin Exp Immunol. 2000;122(3):464-470.

55. Hale MB, Krutzik PO, Samra SS, Crane JM, Nolan GP. Stage dependent aberrant regulation of cytokine-STAT signaling in murine systemic lupus erythematosus. PLoS One. 2009;4(8):e6756.

56. Ishida H, Muchamuel T, Sakaguchi S, Andrade S, Menon S, Howard M. Continuous administration of anti-interleukin 10 antibodies delays onset of autoimmunity in NZB/W F1 mice. J Exp Med. 1994;179(1):305-310.

57. Jacob N, Stohl W. Cytokine disturbances in systemic lupus erythematosus. Arthritis Res Ther. 2011;13(4):228.

58 . Liu J, et al. Genomic view of systemic autoimmunity in MRLlpr mice. Genes Immun. 2006;7(2):156-168.

59. Llorente $\mathrm{L}$, et al. Clinical and biologic effects of anti-interleukin-10 monoclonal antibody administration in systemic lupus erythematosus. Arthritis Rheum. 2000;43(8):1790-1800.

60. Mok CC, Lau CS. Pathogenesis of systemic lupus erythematosus. J Clin Pathol. 2003;56(7):481-490.

61. Viallard JF, et al. Th1 (IL-2, interferon-gamma (IFN- $\gamma$ )) and Th2 (IL-10, IL-4) cytokine production by peripheral blood mononuclear cells (PBMC) from patients with systemic lupus erythematosus (SLE). Clin Exp Immunol. 1999;115(1):189-195.

62. Yap DY, Lai KN. Cytokines and their roles in the pathogenesis of systemic lupus erythematosus: from basics to recent advances. J Biomed Biotechnol. 2010;2010:365083.

63. Moulton VR, Tsokos GC. T cell signaling abnormalities contribute to aberrant immune cell function and autoimmunity. JClin Invest.
2015;125(6):2220-2227.

64. Nguyen TV, Ke Y, Zhang EE, Feng GS. Conditional deletion of Shp2 tyrosine phosphatase in thymocytes suppresses both pre-TCR and TCR signals. J Immunol. 2006;177(9):5990-5996.

65. Luo Q, et al. Blocking initial infiltration of pioneer CD8(+) T-cells into the CNS via inhibition of SHP-2 ameliorates experimental autoimmune encephalomyelitis in mice. Br J Pharmacol. 2014;171(7):1706-1721.

66. Leibson PJ. The regulation of lymphocyte activation by inhibitory receptors. Curr Opin Immunol. 2004;16(3):328-336.

67. Henshall TL, Jones KL, Wilkinson R, Jackson DE. Src homology 2 domain-containing proteintyrosine phosphatases, SHP-1 and SHP-2, are required for platelet endothelial cell adhesion molecule-1/CD31-mediated inhibitory signaling. J Immunol. 2001;166(5):3098-3106.

68. Yokosuka T, Takamatsu M, Kobayashi-Imanishi W, Hashimoto-Tane A, Azuma M, Saito T. Programmed cell death 1 forms negative costimulatory microclusters that directly inhibit $\mathrm{T}$ cell receptor signaling by recruiting phosphatase SHP2. JExp Med. 2012;209(6):1201-1217.

69. Tivol EA, Borriello F, Schweitzer AN, Lynch WP, Bluestone JA, Sharpe AH. Loss of CTLA-4 leads to massive lymphoproliferation and fatal multiorgan tissue destruction, revealing a critical negative regulatory role of CTLA-4. Immunity. 1995;3(5):541-547.

70. Waterhouse $P$, et al. Lymphoproliferative disorders with early lethality in mice deficient in Ctla-4. Science. 1995;270(5238):985-988.

71. Nishimura H, Nose M, Hiai H, Minato N, Honjo T. Development of lupus-like autoimmune diseases by disruption of the PD-1 gene encoding an ITIM motif-carrying immunoreceptor. Immunity. 1999;11(2):141-151.

72. Nishimura H, et al. Autoimmune dilated cardiomyopathy in PD-1 receptor-deficient mice. Science. 2001;291(5502):319-322.

73. Deng C, et al. Hydralazine may induce autoimmunity by inhibiting extracellular signal-regulated kinase pathway signaling. Arthritis Rheum. 2003;48(3):746-756.

74. Gorelik G, Fang JY, Wu A, Sawalha AH, Richardson B. Impaired $\mathrm{T}$ cell protein kinase $\mathrm{C}$ delta activation decreases ERK pathway signaling in idiopathic and hydralazine-induced lupus.
JImmunol. 2007;179(8):5553-5563.

75. Fernandez D, Perl A. mTOR signaling: a central pathway to pathogenesis in systemic lupus erythematosus? Discov Med. 2010;9(46):173-178.

76. Foster JG, Blunt MD, Carter E, Ward SG. Inhibition of PI3K signaling spurs new therapeutic opportunities in inflammatory/autoimmune diseases and hematological malignancies. Pharmacol Rev. 2012;64(4):1027-1054.

77. Suarez-Fueyo A, et al. Inhibition of PI3Kdelta reduces kidney infiltration by macrophages and ameliorates systemic lupus in the mouse. J Immunol. 2014;193(2):544-554.

78. Balomenos D, Rumold R, Theofilopoulos AN. Interferon-gamma is required for lupus-like disease and lymphoaccumulation in MRL-lpr mice. J Clin Invest. 1998;101(2):364-371.

79. Sarkar S, et al. Interleukin (IL)-17A, F and AF in inflammation: a study in collagen-induced arthritis and rheumatoid arthritis. Clin Exp Immunol. 2014;177(3):652-661.

80. Jain M, et al. Increased plasma IL-17F levels in rheumatoid arthritis patients are responsive to methotrexate, anti-TNF, and T cell costimulatory modulation. Inflammation. 2015;38(1):180-186.

81. Zeller GC, Hirahashi J, Schwarting A, Sharpe AH, Kelley VR. Inducible co-stimulator null MRL-Faslpr mice: uncoupling of autoantibodies and T cell responses in lupus. J Am Soc Nephrol. 2006;17(1):122-130.

82. Ozmen L, Roman D, Fountoulakis M, Schmid G, Ryffel B, Garotta G. Experimental therapy of systemic lupus erythematosus: the treatment of NZB/W mice with mouse soluble interferongamma receptor inhibits the onset of glomerulonephritis. Eur J Immunol. 1995;25(1):6-12.

83. Mishra N, Brown DR, Olorenshaw IM, Kammer GM. Trichostatin A reverses skewed expression of CD154, interleukin-10, and interferon- $\gamma$ gene and protein expression in lupus T cells. Proc Natl Acad Sci U S A. 2001;98(5):2628-2633.

84. Grammatikos AP, et al. A T cell gene expression panel for the diagnosis and monitoring of disease activity in patients with systemic lupus erythematosus. Clin Immunol. 2014;150(2):192-200.

85. Kontaridis MI, Swanson KD, David FS, Barford D, Neel BG. PTPN11 (Shp2) mutations in LEOPARD syndrome have dominant negative, not activating, effects. J Biol Chem. 2006;281(10):6785-6792. 